\title{
MEMORANDUM
}

No 05/2015

\section{Natural Resources and Sovereign Expropriation}

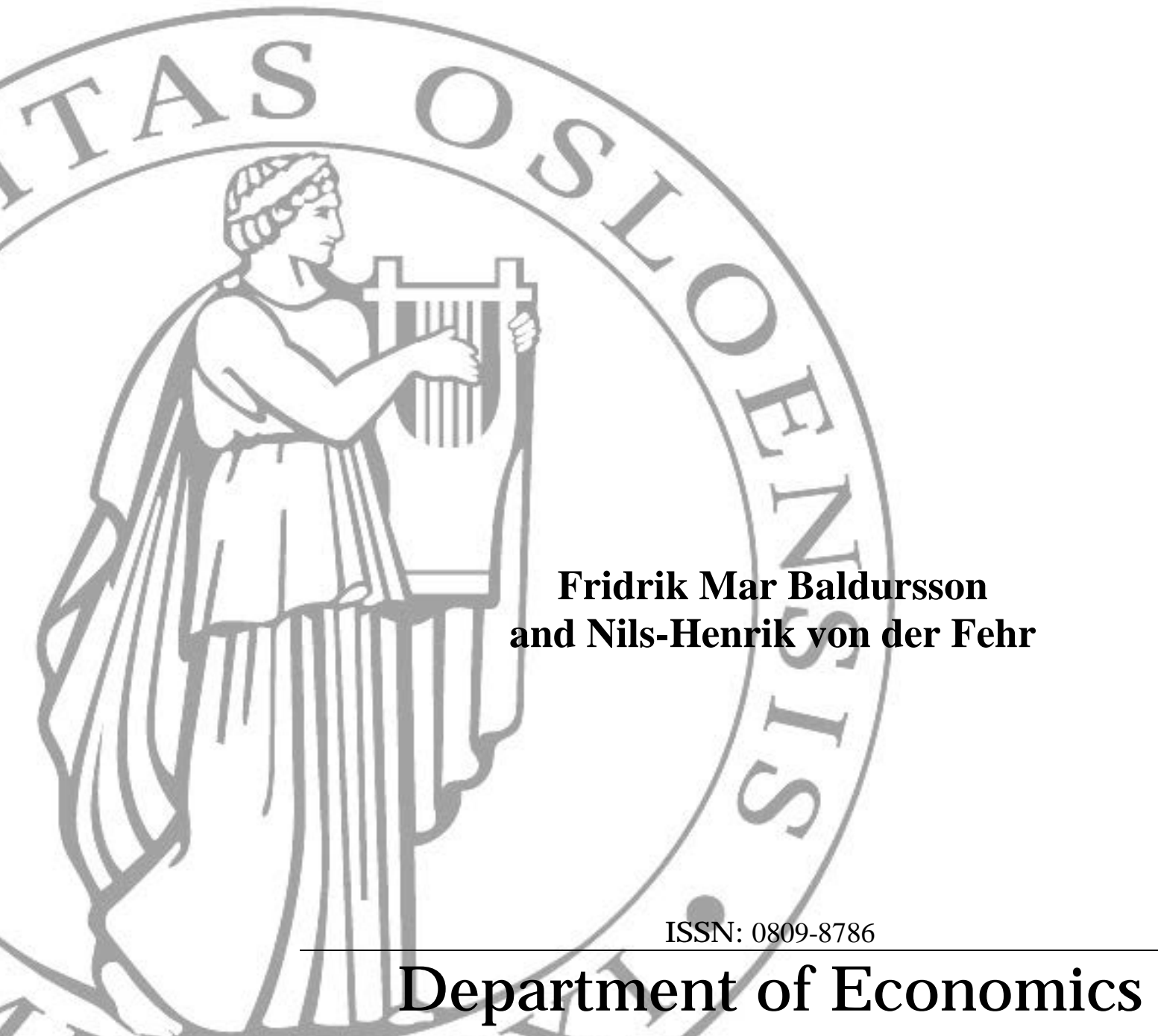

University of O slo 
This series is published by the

\section{University of Oslo Department of Economics}

P. O.Box 1095 Blindern

N-0317 OSLO Norway

Telephone: + 4722855127

Fax: $\quad+4722855035$

Internet: http://www.sv.uio.no/econ

e-mail: $\quad$ econdep@econ.uio.no
In co-operation with

The Frisch Centre for Economic

Research

Gaustadalleén 21

N-0371 OSLO Norway

Telephone: $\quad$ +4722958820

Fax: $\quad+4722958825$

Internet: $\quad$ http://www.frisch.uio.no

e-mail: $\quad$ frisch@frisch.uio.no

\section{Last 10 Memoranda}

\begin{tabular}{|c|c|}
\hline No $04 / 15$ & $\begin{array}{l}\text { Erik Biørn and Xuehui Han } \\
\text { Persistence, Signal-Noise Pattern and Heterogeneity in Panel Data: With } \\
\text { an Application to the Impact of Foreign Direct Investment in GDP }\end{array}$ \\
\hline No $03 / 15$ & $\begin{array}{l}\text { Alice Ciccone } \\
\text { Environmental Effects of a Vehicle Tax Reform: Empirical Evidence from } \\
\text { Norway }\end{array}$ \\
\hline No $02 / 15$ & $\begin{array}{l}\text { Katinka Holtsmark and Kristoffer Midttømme } \\
\text { The Dynamics of Linking Permit Markets }\end{array}$ \\
\hline No $01 / 15$ & $\begin{array}{l}\text { Francesco Lania and Alessia Russo } \\
\text { Public Education and Pensions in Democracy: A Political Economy } \\
\text { Theory }\end{array}$ \\
\hline No 29/14 & $\begin{array}{l}\text { Lars Kirkebøen, Edwin Leuven and Magne Mogstad } \\
\text { Field of Study, Earnings, and Self-Selection }\end{array}$ \\
\hline No $28 / 14$ & $\begin{array}{l}\text { Erik Biørn } \\
\text { Serially Correlated Measurement Errors in Time Series Regression: The } \\
\text { Potential of Instrumental Variable Estimators }\end{array}$ \\
\hline No $27 / 14$ & $\begin{array}{l}\text { Erik Biørn } \\
\text { The Price-Quantity Decomposition of Capital Values Revisited: } \\
\text { Framework and Examples }\end{array}$ \\
\hline No $26 / 14$ & $\begin{array}{l}\text { Olav Bjerkholt } \\
\text { Econometric Society 1930: How it Got Founded }\end{array}$ \\
\hline No $25 / 14$ & $\begin{array}{l}\text { Nils Chr. Framstad } \\
\text { The Effect of Small Intervention Costs on the Optimal Extraction of } \\
\text { Dividends and Renewable Resources in a Jump-Diffusion Model }\end{array}$ \\
\hline No $24 / 14$ & $\begin{array}{l}\text { Leif Andreassen, Maria Laura Di Tommaso and Steinar Strøm } \\
\text { Wages Anatomy: Labor Supply of Nurses and a Comparison with } \\
\text { Physicians }\end{array}$ \\
\hline
\end{tabular}

Previous issues of the memo-series are available in a PDF® format at: http://www.sv.uio.no/econ/english/research/unpublished-works/working-papers/ 


\title{
Natural Resources and Sovereign Expropriation
}

\author{
Fridrik Mar Baldursson \\ Reykjavik University and University of Oslo \\ Nils-Henrik M von der Fehr \\ University of Oslo \\ Memo 05/2015-v1 \\ (this version February 15, 2015)
}

\begin{abstract}
A government wants to exploit a renewable resource, yielding a timevarying flow of rent, by leasing it at a fixed rate. Leasing contracts can be expropriated before expiration, albeit at a cost. To minimise transactions costs and avoid the 'resource curse' the government would prefer to enter into an infinitely long contract (i.e. sell the resource), if it could commit not to expropriate. However, with finite costs of expropriation credible commitment is impossible: the government either enters into finite contracts, expropriates with positive probability or does both. The value of the resource to the government is increasing in the cost of expropriation, but decreasing in the variability of the resource rent. ${ }^{1}$

Keywords: Natural resources, sovereign expropriation, optimal contract length. JEL codes: H13, Q2, D86
\end{abstract}

\section{Introduction}

When, in 2011, the Parliament of Iceland enacted a time limit on rights to use publicly owned water resources, a major concern was to prevent situations where the state would permanently relinquish its resources to private parties, possibly losing

\footnotetext{
${ }^{1}$ Baldursson: fmb@ru.is; von der Fehr: nhfehr@econ.uio.no.

We thank Bård Harstad, Daniel Spiro and seminar participants at the Aalto University and the University of Oslo for constructive feedback on earlier versions of the paper; Fridrik Baldursson worked on the paper while a visitor at Aalto in the Fall of 2013. While carrying out this research both authors have been associated with CREE-Oslo Centre for Research on Environmentally friendly Energy. CREE is supported by the Research Council of Norway.
} 
completely out on a large future increase in resource value. ${ }^{2,3}$ These considerations must be seen in the light of experience from situations where the government was induced to force renegotiation of contractual terms. ${ }^{4}$ The case of Icelandic water resources is of course not unique: around the world governments have placed time limits on exploitation of natural resources in order to reduce the risk of being compelled to renege on contractual commitments or expropriate private gains and the inevitable costs of such actions. ${ }^{5}$

In this paper, we study the problem of setting time limits on rights to use renewable resources. In our model, a government holds a natural resource that yields a time-varying flow of rent for all future. The government offers a leasing contract through a competitive market that allows the leaseholder to receive the resource rent against a lease rate that is fixed over the term of the lease. Contracts can be infinitely long (an infinitely long contract may be thought of as privatisation of the resource), but may also be finite, in which case transaction costs are incurred every time a new contract is entered into. ${ }^{6}$ Contracts can be expropriated or terminated at any time until they expire but this entails an additional cost to the government. ${ }^{7}$

We show that optimal contracts either have finite maturity or they will be expropriated with positive probability. When the resource rent grows at a fixed, positive rate optimal contracts are of finite maturity that is set as long as possible without making expropriation advantageous. When the resource rent is stochastic optimal contracts do, however, involve expropriation, but with low probability. A long con-

\footnotetext{
${ }^{2}$ Water resources, which can be exploited to produce electricity in hydro- or geothermal power plants, are abundant in Iceland. Most of these resources are on public lands.

${ }^{3}$ This may be seen in light of the fact that in the 1980's fishing rights in Iceland were bound in individual transferable quotas which were grandfathered without any time limitation on the rights. These rights have risen enormously in value since the system was put in place, with the resulting increase accruing to owners of fishing vessels.

${ }^{4}$ An example of such a situation is provided by a dispute between the Government of Iceland and Alusuisse (now a part of Rio Tinto Alcan) in the early 1980's. The dispute revolved around taxation as well as price of electricity produced by a state-owned electricity producer to power Alusuisse's aluminium smelter in Iceland. Both taxes and electricity prices had been negotiated in the 1960's - before the oil crises of the 1970's had drastically changed international energy prices and other economic factors. The dispute, which was initiated by the Government of Iceland, lasted more than three years and ended in 1984 with a renegotiated contract with terms substantially more advantageous to Iceland than those of the previous contract.

${ }^{5}$ For water, Norway presents another example, with its statutory time limits on licences to private parties for exploring hydrological resources for power production. In fisheries, it has become common to regulate catch by allocating private property rights in the form of time-limited quotas, see Costello and Kaffine (2008) for examples.

${ }^{6}$ There may be other costs associated with finite contract length, such as inefficient resource use, which could be higher the shorter the contract is. We abstract from such costs in the formal analysis but return to the issue in the Conclusion; in the Appendix, we outline an extension of the formal analysis to show how such costs could be incorporated.

${ }^{7}$ The model is in fact quite general. With slight reformulation, it could be applied to nonrenewable resources such as oil extraction or REDD contracts for conserving tropical forests.
} 
tract has the advantage of reducing transaction costs, while a short contract has the advantage of reducing (expected) cost of expropriation; the optimal contract balances these two types of costs.

The (net) value of the resource is the present value of rent less costs of entering into contracts and, possibly, expropriating them. Hence, resource value would be maximised if the government could commit to an infinitely long contract that would not be expropriated. With imperfect commitment - that is, finite cost of expropriation - this is not possible and so the government is caught in a 'natural resource trap'; in particular, a government that incurs a low cost of expropriation must pay for this through short contracts, high transaction costs and low lease rates. A lower cost of expropriation therefore reduces the value of the resource. ${ }^{8}$

Myopia also reduces the value of the resource. With a high discount rate the government puts less weight on future costs of expropriation. Contract maturity is therefore increased and expropriation occurs more frequently, reducing resource value.

Expropriation occurs at high resource rents, which are more likely when volatility is high. The government counteracts increased frequency of expropriation with contracts of shorter maturity. In other words, it is optimal to write shorter contracts for natural resources with greater rent variation; nevertheless, greater variability reduces the value of the resource.

Finally, high costs of entering into contracts lead to long maturity and, hence, a high incidence of expropriation. Resource value is low due both to high transaction costs and the induced expropriation costs.

Our analysis is related to the literature on pricing expropriation risk in natural resource contracts, particularly the real options approach of Schwarz and Trolle (2010), from which we have also borrowed certain modelling elements (earlier work in this tradition includes Mahajan, 1990, and Clark, 2003). They consider a finitehorizon set up in which a government enters into a contract for production from a natural resource for the entire time period. The government may at any given time take over production for the remainder of the period, albeit at some cost. Among other results, Schwarz and Trolle show that, for a given contractual arrangement, the value of the expropriation option increases with volatility of the output price. When we take account of the recurrent nature of the contracting problem, as well

\footnotetext{
${ }^{8}$ The risk of expropriation is an instance of an imperfection in property rights. Arnason (2012) gives an overview of the dimensions of property rights and discusses the associated costs of imperfections. While there are efficiency arguments for well defined and secure property rights, we take it as given that governments will expropriate when the benefits of doing so exceed the costs and consider the consequences for market equilibrium.
} 
as the endogeneity of contractual terms (maturity and lease rate), we come to the opposite conclusion: increased volatility does in fact reduce resource value.

We also contribute to the literature on optimal resource extraction contracts under threat of expropriation (see eg. Aghion and Quesada, 2010, Engel and Fischer, 2010, and Wernerfelt and Zeckhauser, 2010, for introductions to the literature, as well as more specific analyses). ${ }^{9}$ This literature has considered a range of different dimensions of the contracting problem, including sharing of production, profits and ownership, as well as various limits on payments to the leaseholder, but not the maturity or duration of contracts. ${ }^{10}$ In order to concentrate on the maturity issue, and for analytical tractability, we abstract from other contractual dimensions and simply assume that payments are based on a fixed lease rate (see below for more on this assumption).

The literature on natural resources and sovereign expropriation has been much concerned with the underlying political economy of what Lawrence Summers has called the 'privatisation trap': nations with low credibility are forced to offer advantageous terms to firms in order to attract foreign direct investment (Summers, 2010). ${ }^{11}$ But when profits are high even well-meaning, well-intentioned governments will come under political pressure to renege on contracts in order to bring the profits back to their own constituency. By taking government preferences as given and constant over time, we abstract from many aspects of the political economy issue. ${ }^{12}$ However, we do capture, in an admittedly stylised manner, the ability to withstand pressure - which in practice is determined in complex interactions between institutions, political processes and public perceptions - and analyse how it affects not only the extent of expropriation but also contractual relations between governments and private investors, including the possibility of privatisation.

Our work is related to the literature on strategic sovereign debt and default, ${ }^{13}$

\footnotetext{
${ }^{9}$ In this context, 'contract' encompasses taxes, regulations and other relevant aspects of the business environment subject to government control or influence.

${ }^{10} \mathrm{~A}$ strand of this literature studies self-enforcing long-term contracting in an stationary, infinitely-repeated, bilateral-monopoly game in which the leaseholder has to make investments at each stage and breach of contract leads to autarky (Thomas and Worrall, 1994). We abstract from such investments and consider the case in which the distribution of states is non-stationary and the government may turn to an alternative partner when a given contract expires or is expropriated.

${ }^{11}$ See the collection of papers edited by Hogan and Sturzenegger (2010) for theoretical and empirical papers on the expropriation issue in the context of natural resources. They use the term 'natural resource trap' for the privatisation trap in the natural resource context. See also Hajzler (2012) for an overview of sectoral patterns of expropriation.

${ }^{12}$ See eg. Di Tella, Dubra and MacCulloch (2010) on the interaction between economic conditions on the one hand and social beliefs and political attitudes on the other.

${ }^{13}$ Tomz and Wright (2010) present historical evidence for both expropriation and default and show that defaulting states tend also to expropriate. They also analyse how incentives to default and expropriate vary with the economic cycle, risk aversion of governments, and costs of default
} 
going back to the seminal paper of Eaton and Gersovits (1981). ${ }^{14}$ Of particular relevance to our work is recent research by Arellano and Ramanarayanan (2012) who study a dynamic model of sovereign borrowing with endogenous default and interest rate spreads and two possible bond maturities, short-term and long-term. They show that long-term debt provides a hedge against future fluctuations in spreads, whereas short-term debt provides better incentives to repay. This has implications for the maturity structure of sovereign debt.

We are aware of only three other papers that explicitly consider the issue of (optimal) contract length. Harris and Holmström (1987) associate length with time between renegotiation of a given contract and considers a setting where costly renegotiation is necessary to discover and incorporate new information. Ellman (2006) studies the tradeoff between incentives for relation-specific investments and the benefit of switching to a better partner. Harstad (2015) argues that the optimal length of climate agreements trades off the hold-up problem of inefficient technology investment incentives against the problem of choosing the right amount of emission quotas. None of these papers allows for strategically breaching a contract to enter into a new, more advantageous one, as we do.

The paper is organised as follows. In Section 2, we set up a general model and in Section 3 formalise the resource trap; in Section 4, we consider a deterministic version of the model, and in Section 5 the general case with stochasticity; finally, in Section 6, we conclude.

\section{The Set Up}

The government holds a natural resource. The resource is infinitely lived and renewable and generates a resource rent flow of $R_{t}$ at time $t$. $R_{t}$ should be thought of as revenues emanating from the resource net of costs of exploitation.

Time is continuous and $R_{t}$ is a geometric Brownian motion, i.e. has the stochastic differential equation (SDE) representation

$$
d R_{t}=\mu R_{t} d t+\sigma R_{t} d W_{t}
$$

where $W=\left\{W_{t} ; t \geq 0\right\}$ is a Brownian motion defined on the complete probability space $(\Omega, \Im, P)$ and $\mu$ and $\sigma \geq 0$ are return and volatility parameters. Starting from a given initial value $r_{0}$, the SDE has the unique solution, $R_{t}=r_{0} e^{\left(\mu-\sigma^{2} / 2\right) t+\sigma W_{t}} \cdot{ }^{15}$

and expropriation.

${ }^{14}$ See Panizza et al. (2010) for a recent review of this literature.

${ }^{15}$ Hence, $\ln \left(R_{t}\right)$ is a Brownian motion with trend parameter $\mu-\frac{\sigma^{2}}{2}$ and per-unit-time standard 
Denote by $\left\{\Im_{t} ; t \geq 0\right\}$ the nondecreasing, right-continuous family of sub- $\sigma$-algebras of $\Im$ ("filtration") associated with $W$. $\Im_{t}$ contains all events depending on features of sample paths up to time $t$, or, even more informally, information on all events that have taken place up to time $t$. Finally, we assume that $\mu<\delta$, where $\delta$ is a discount rate, so that the expected present value of the resource rent is finite

$$
V_{0}=E\left[\int_{0}^{\infty} e^{-\delta t} R_{t} d t\right]<\infty
$$

In the deterministic case, $\sigma=0$ and (2.1) reduces to the ordinary differential equation $\dot{R}_{t}=\mu R_{t}$ which, starting from a given initial value $r_{0}$, has the unique solution, $R_{t}=r_{0} e^{\mu t}$.

\subsection{Leasing contracts}

The government prefers not to exploit the resource on its own but signs leasing contracts for its exploitation. ${ }^{16}$ At any time after a contract comes into effect, but before it expires, when observing the realised rent the government may decide to expropriate the resource and lease it again. To formalise this, let $T \geq 0$ be the contractual expiration time (maturity) of the first contract, and let $\tau \geq 0$ be the time of expropriation of the first contract. The expropriation time $\tau$ must be a stopping time, i.e. the decision to expropriate at a certain time can depend on observed resource rent up to that time. ${ }^{17}$ If there is no expropriation, so that the contract is allowed to expire, we set $\tau=T$. We therefore have

$$
0 \leq \tau \leq T
$$

with $\tau<T$ if there is expropriation and $\tau=T$ if the contract expires without expropriation.

Expropriation of a contract at time $t \geq 0$ carries the cost $k R_{t}$ where $k$ is a positive constant. This assumption has the advantage of being mathematically convenient,

deviation $\sigma$. Throughout we use upper case $R$ for the stochastic process and lower case $r$ for a given (deterministic) value of $R$ at a certain time.

${ }^{16}$ This could be because the government lacks the relevant knowhow; see the various contributions in Hogan and Sturzenegger (2010) for examples and discussions.

${ }^{17}$ In other words, $\tau$ must be measurable with respect to the $\sigma$-algebra $\Im_{\tau}$. The mathematical concept of a stopping time in the theory of stochastic processes formalises the idea that the decision to 'stop' and undertake some action should be based on information available at the time of decision only and not rely on future events (Karatzas and Shreve, 1991). To establish that $\tau_{i}$ is a stopping time it suffices to show that $\{\tau>t\} \in \Im_{t}$ for all $t>0$, i.e. for each $t$ the event where the decision to stop has not been made at time $t$ must be contained in the $\sigma$-algebra generated by all possible sample-paths up to time $t$. 
but it also captures the idea that the costs of expropriation are related to the value of the resource, i.e. what is at stake (cf. Engel and Fischer, 2010). We think of costs of expropriation not only as including direct costs, such as legal costs in relation to litigation, but also indirect costs due to the perception of increased risk of investment, deterioration in terms of trade, political implications, and so on (cf. Hogan and Sturzenegger, 2010). ${ }^{18}$ Similarly, we assume that the costs of entering into a contract at time $t$ and begin exploiting the resource are given by $c R_{t}$, where $c$ is a positive constant. Without loss of generality we let the entire cost of entering into a contract fall on the leaseholder, cf. Equation (3.2). However, we think of $c$ as the total cost of transaction, including the cost to the government of assessing the value of the resource or rent at the time the contract is written as well as the cost to the firm of setting up operations. It seems reasonable that some of these costs are increasing in the value of the resource; for example, a higher resource rent caused by a global demand shock would tend to raise the costs of setting up operations.

The government is restricted to a contract form with a flow of payment (lease rate) $l r$ over a contract period starting at time $t_{0}$, where $l$ is a positive constant and $R_{t_{0}}=r$. For simplicity, we assume a fixed lease rate over the lifetime of each contract (although the lease rate will be changed with each new contract that is entered into). ${ }^{19}$

Note that we assume that payments cannot be conditioned on the value of the resource during the contract period while the decision to expropriate can. In real situations, governments typically cannot observe the resource rent (in particular underlying costs of exploitation), but they may observe various signals that are correlated with it (such as product price indices). It may be possible to index payments to some such signals (e.g. royalties linked to product price indices), but this would rarely capture all rents. ${ }^{20}$ Therefore, even in such a richer set up there would be an incentive to expropriate for sufficiently strong signals. For our analysis, the critical assumption is that the government cannot fully extract resource rent in all contin-

\footnotetext{
${ }^{18}$ In our full-information setting, we cannot capture possible reputation effects of expropriation that affect behaviour of actual and potential leaseholders. Modelling such effects would require a setting with asymmetric information about the 'type' of the government, or the value of $k$ in our model, in effect endogenising $k$. However, even accounting for such effects, in a world where reputation is short-lived (for example because it is only related to the current government) it is not unreasonable to assume that $k$ remains constant over time.

${ }^{19}$ Rigobon (2010) discusses various reasons why payments for the exploitation of natural resources do not typically vary completely with underlying rents or profits, including agency issues and the desire of governments to stabilise revenues.

${ }^{20}$ Engel and Fisher (2010) write: "Attempts have been made to introduce profit-sharing mechanisms to reduce the temptation to expropriate, but in practice they are often abused by transfer pricing, creating negative effect on public opinion, which in turn increases the pobability of expropriation."
} 
gencies through contractual arrangements, including royalty payments, taxes and the like, and hence that it has an incentive to expropriate in some circumstances. Rather than considering a more complex environment where complete capture of rents would not be possible for any conceivable contract (e.g. along the lines of Harris and Holmström, 1987), we have chosen a simpler, incomplete-contracting framework where the set of available contracts is constrained. In particular, we have made the assumption that expropriation and transaction costs are proportional to the resource rent while the lease rate is fixed over the contract period. Alternatively, we could have allowed for a variable lease rate (e.g. by profit sharing) and assumed that costs were fixed; such a formulation yields similar incentive for expropriation, but it involves a time-inhomogenous model that is analytically intractable. While we have chosen a formulation that is analytically convenient, the insights would seem to carry over to a more general setting.

\subsection{Government surplus}

Given a contracting strategy, i.e. sequences of contract expiration times, $\left\{T_{i}\right\}$, and expropriation times, $\left\{\tau_{i}\right\}$, and a sequence of lease rates, $\left\{l_{i}\right\}$, the government's surplus, summing over all future contracts, can be written as

$$
G=E\left[\sum_{i=1}^{\infty}\left(\int_{\tau_{i-1}}^{\tau_{i}} e^{-\delta t} l_{i} R_{\tau_{i-1}} d t-e^{-\delta \tau_{i}} 1_{\left\{\tau_{i}<T_{i}\right\}} k R_{\tau_{i}}\right) \mid R_{0}=r_{0}\right]
$$

where $\tau_{0}=0 .^{21}$

We can rewrite $(2.2)$ as

$$
G=r_{0} E\left[\sum_{i=1}^{\infty}\left(\int_{\tau_{i-1}}^{\tau_{i}} e^{-\delta t} l_{i} \hat{R}_{\tau_{i-1}} d t-e^{-\delta \tau_{i}} 1_{\left\{\tau_{i}<T_{i}\right\}} k \hat{R}_{\tau_{i}}\right) \mid \hat{R}_{0}=1\right]
$$

where $\hat{R}_{t}=R_{t} / r_{0}$. Note that $\hat{R}$ obeys (2.1) with the initial value $\hat{R}_{0}=1$. It follows that $G$ is homogenous in $r_{0}$. It therefore suffices to find an equilibrium solution starting from $r_{0}=1$.

Now rewrite (2.2) by separating the first term from the remainder of the infinite sum, factoring $R_{\tau_{1}} e^{-\delta \tau_{1}}$ out of the sum and taking conditional expectation,

\footnotetext{
${ }^{21}$ In line with the earlier literature (cf. Engel and Fischer, 2010), we (implicitly) assume that the leaseholder is foreign so that goverment surplus does not include profits. The qualitative nature of our results would appear to hold also if profits were included, so long as these had lower weight than government revenue.
} 
conditioning on information available at $\Im_{\tau_{1}}$ (i.e. on $R_{\tau_{1}}$ ),

$$
\begin{aligned}
& G=E\left[\int_{0}^{\tau_{1}} e^{-\delta t} l_{1} d t-e^{-\delta \tau_{1}} 1_{\left\{\tau_{1}<T_{1}\right\}} k R_{\tau_{1}}\right. \\
& \left.+R_{\tau_{1}} e^{-\delta \tau_{1}} E\left[\sum_{i=2}^{\infty}\left(\int_{\tau_{i-1}}^{\tau_{i}} e^{-\delta\left[t-\tau_{1}\right]} l_{i} \check{R}_{\tau_{i-1}} d t-e^{-\delta\left[\tau_{i}-\tau_{1}\right]} 1_{\left\{\tau_{i}<T_{i}\right\}} k \check{R}_{\tau_{i}}\right) \mid R_{\tau_{1}}\right] \mid R_{0}=1\right],
\end{aligned}
$$

where $\check{R}_{t}=R_{t} / R_{\tau_{1}}$. By the Markov property and time-homogeneity of the geometric Brownian motion the inner conditional expectation reduces to $G$ starting from $\tau_{1}$ and so we can write

$$
G=E\left[\int_{0}^{\tau_{1}} e^{-\delta t} l_{1} d t-e^{-\delta \tau_{1}} 1_{\left\{\tau_{1}<T_{1}\right\}} k R_{\tau_{1}}+R_{\tau_{1}} e^{-\delta \tau_{1}} G\right]
$$

The first two terms inside the expectation on the right-hand side represent the value of the first contract, allowing for the possibility of expropriation. The last term is the discounted value of the resource starting at the time of expiration or expropriation of the first contract.

It is now clear that the problem 'starts anew' at $\tau_{1}$. In this formulation the resource rent process begins at 1 in each contract period, the optimal contract length $T$ will be the same for all contract periods, and the expropriation time in each contract period will have the same distribution, or, put in terms of sample paths of the resource rent, be the same functional of the sample path.

\subsection{Determination of lease rates}

There is perfect competition for leasing utilisation rights. Given a contract length $T$ and an expropriation strategy $\tau$, expected profit to the holder of the first contract (leaseholder) is given by

$$
\pi=E\left[\int_{0}^{\tau} e^{-\delta t}\left(R_{t}-l\right) d t-c\right]
$$

where $c$ is the cost of entering into a leasehold and we have normalised the inital resource rent to $R_{0}=1$.

Since there is perfect competition for leasing the resource, we have the condition that

$$
\pi=0
$$


which implies

$$
l=\frac{\delta E\left[\int_{0}^{\tau} e^{-\delta t} R_{t} d t-c\right]}{1-E e^{-\delta \tau}} .
$$

Applying Ito's rule to $e^{-\delta t} R_{t}$ it is immediate that

$$
e^{-\delta t} R_{t}-R_{0}=-(\delta-\mu) \int_{0}^{t} e^{-\delta s} R_{s} d s+\sigma \int_{0}^{t} e^{-\delta s} R_{s} d W_{s}
$$

which gives the following expression for $l$ :

$$
l=\frac{\delta}{\delta-\mu} \frac{1-E e^{-\delta \tau} R_{\tau}-c(\delta-\mu)}{1-E e^{-\delta \tau}}
$$

provided that the stopping time $\tau$ has finite expectation.

\subsection{Equilibrium}

We may think of the government's decision problem as occurring in two stages: first, the government selects a maturity for the contract, and second, during the lifetime of the contract, it must decide on when to terminate the contract, i.e. whether to expropriate or allow the contract to expire.

First consider the problem of expropriation of a contract. Fix the contract length $T$, take the lease rate $l$ as given and define the optimal payoff, or value function

$$
V=\sup _{\tau \leq T} G
$$

where the supremum is taken over all stopping times $\tau \leq T$. By (2.5), $V$ must satisfy the equation ${ }^{22}$

$$
V=\sup _{\tau \leq T} E\left[\int_{0}^{\tau} e^{-\delta t} l d t-e^{-\delta \tau} 1_{\{\tau<T\}} k R_{\tau}+R_{\tau} e^{-\delta \tau} V \mid R_{0}=1\right] .
$$

The equilibrium in this model is given by an optimal contract of length $T^{*}$ that maximises the (net) value of the resource, $V$, an expropriation time, $\tau^{*}$, that solves (2.11) and a lease rate, $l^{*}$, determined by the zero-profit condition $(2.7) .{ }^{23}$

\footnotetext{
${ }^{22}$ Note that $V$ is the value of the option to terminate the contract by expropriation. Analytically it is similar to an American call option with a particular payoff structure. We elaborate on this point in Section 5.1 below.

${ }^{23}$ The equilibrium is renegotiation proof provided that contracting costs, $c$, and expropriation costs, $k$, apply in the relevant circumstances. In particular, it seems reasonable that any attempt to renege on the contract - whether by outright expropriation or to obtain more favourable terms through renegotiation - is considered a breach of contract that carries costs; here, for simplicity, we assume that these costs are the same, and equal to $k$, for any type of breach.
} 
Table 1: Baseline parameter values

\begin{tabular}{|c|c|}
\hline Cost of expropriation & $k=1$ \\
\hline Cost of contracting & $c=0.5$ \\
\hline Discount rate & $\delta=0.1$ \\
\hline Resource rent growth rate & $\mu=0.02$ \\
\hline Resource rent volatility & $\sigma=0.1$ \\
\hline
\end{tabular}

\subsection{Parametrisation}

Below we present numerical results for a parametrised version of the model. For our baseline case, we use the parameter values given in Table 1. Thinking of time as measured in years, the resource rent has a growth rate of two per cent and a volatility of 10 per cent, while the discount rate is 10 per cent. The cost of expropriation corresponds to resource rent for one year while the cost of contracting is half of that.

Actual parameter values will of course vary depending on the specific circumstances, such as country, resource and market conditions. We have attempted to select baseline values that are within a reasonable range.

Prices of commodities produced on the basis of renewable resources can provide an indication of the dynamics of the underlying resource rent. For example, over the last thirty years the real world-price of fish meal has a trend of 3.8 per cent and volatility of 15 per cent p.a.; the corresponding numbers for aluminium (an important driver of hydro rents) are -0.4 and 19.1 per cent and for timber 0.9 and 12.2 per cent. $^{24}$

We have assumed the government and market participants use the same discount rate. Indeed, in many countries governments employ a market-based discount rate for projects which could be implemented by private parties. In developed economies, this tends to put the discount rate in the range of 7-10 per cent; in developing economies rates are often higher. ${ }^{25}$

Clearly, the cost of expropriation will depend critically on conditions prevailing at the time it happens. Taking wider repercussions into account - e.g. possible market exclusion, capital flight or retaliation - the cost may well become large; in particular, it does not seem unreasonable that it is of a similar order of magnitude as the net rent of a particular natural resource over one year. ${ }^{26}$

\footnotetext{
${ }^{24}$ These values are calculated based on monthly data from UNCTAD (fish meal and aluminium) and the World Bank (timber), deflated by the US Produer Price Index.

${ }^{25}$ See discussion in Zhuang et al. (2007).

${ }^{26}$ In the literature on sovereign default it is common to assume the cost of default to be a fraction of output. For example, Aguiar and Gopinath (2006) assume a value of $5 \%$ of a year's worth of gross domestic product, Arellano and Ramanarayanan (2012) 4.5\% while Hatchondo and Martinez
} 
Similarly, the cost of contracting - which includes not only the pure transaction cost, but also costs of setting up operations and making necessary investments - will depend on conditions but may well be large; we assume it to be 50 per cent of the net annual resource rent at the initiation of utilisation.

Obviously, other parameter values could have been argued for. However, as we shall see below, the qualitative nature of our results is robust to the choice of parameter values as long as they are within reasonable bounds.

\section{Resource trap}

Inserting (2.6) and (2.7) into (2.2), for an arbitrary contracting strategy we get

$$
G=E\left[\sum_{i=1}^{\infty}\left(\int_{\tau_{i-1}}^{\tau_{i}} e^{-\delta t} R_{t} d t-e^{-\delta \tau_{i-1}} c R_{\tau_{i-1}}-e^{-\delta \tau_{i}} 1_{\left\{\tau_{i}<T_{i}\right\}} k R_{\tau_{i}}\right)\right]
$$

Rewriting this expression, we have

$$
G=E\left[\int_{0}^{\infty} e^{-\delta t} R_{t} d t\right]-E\left[\sum_{i=1}^{\infty}\left(e^{-\delta \tau_{i-1}} c R_{\tau_{i-1}}+e^{-\delta \tau_{i}} 1_{\left\{\tau_{i}<T_{i}\right\}} k R_{\tau_{i}}\right)\right]
$$

The first term on the right-hand side of the equation is the value of the resource given by the expected present value of the resource rent. The second term is the expected present value of costs associated with writing and expropriating contracts. In other words, the government receives the present value of the resource rent less all transaction costs.

It follows that the government's surplus would be maximised if transaction costs could be avoided. If the government could commit never to expropriate a contract, it would. Also, it would want to enter into the longest contracts possible. We can analyse this as the case where the cost of expropriating a contract is infinite.

Suppose $k \equiv \infty$. Then no contracts would be expropriated so $\tau_{i} \equiv T_{i}$ and, hence, (3.2) reduces to

$$
G=E\left[\int_{0}^{\infty} e^{-\delta t} R_{t} d t\right]-E\left[\sum_{i=1}^{\infty} e^{-\delta T_{i-1}} c R_{T_{i-1}}\right]
$$

(We set $T_{0}=0$.) This expression is maximised for $T_{1}=\infty$, i.e. for an infinitely long first contract. This amounts to selling the resource at a price equal to the expected (2009) consider values in the range $2.5-12.5 \%$. 
present value of the resource rent less the cost of making the transaction,

$$
V^{\infty}=E\left[\int_{0}^{\infty} e^{-\delta t} R_{t} d t\right]-c=\frac{1}{\delta-\mu}-c
$$

Now we will show that if the government is unable to commit it may suffer additional transaction costs, either because contracts are of finite maturity or because they will be expropriated.

To see this, suppose a contract of infinite maturity that will never (i.e. with probability zero) be expropriated could be implemented. Then the lease rate $l$ is easily calculated from (2.7) as

$$
l^{\infty}=\delta\left(\frac{1}{\delta-\mu}-c\right)
$$

At any time $t$ the value to the lessee of the remainder of the contract is

$$
E\left[\int_{t}^{\infty} e^{-\delta[s-t]}\left(R_{s}-l\right) d s \mid R_{t}\right]=\frac{1}{\delta-\mu}\left(R_{t}-R_{0}\right)+c .
$$

Define the stopping time $\tau^{\varepsilon}$ as the first time this value exceeds the cost of the government expropriating the contract and entering into a new one by a (small) positive margin $\varepsilon>0$, i.e.

$$
\tau^{\varepsilon}=\inf \left\{t \geq 0: \frac{1}{\delta-\mu}\left(R_{t}-R_{0}\right)+c>(k+c) R_{t}+\varepsilon\right\} .
$$

At this time the government can increase its surplus by expropriating the initial contract and offering a new contract of the same type but with payment flow $\hat{l}>l$. If $\tau^{\varepsilon}<\infty$ with positive probability this contradicts the assumption that the optimal contract is of infinite maturity and will never be expropriated.

The inequality in (3.7) can be rewritten as

$$
\left(\frac{1}{\delta-\mu}-k-c\right) R_{t}>\left(\frac{1}{\delta-\mu}-c\right) R_{0}+\varepsilon .
$$

This inequality will be satisfied for some $t$ with positive probability if and only if ${ }^{27}$

$$
k+c<\frac{1}{\delta-\mu} .
$$

\footnotetext{
${ }^{27}$ For a geometric Brownian motion, the first-passage time to any given level, say $x$, is finite with positive probability, i.e. if we define $\lambda_{x}=\inf \left\{t \geq 0: R_{t} \geq x\right\}$ then $\operatorname{Pr}\left\{\lambda_{x}<\infty\right\}>0$. For a geometric Brownian motion, $R_{t}$, such that $\ln \left(R_{t}\right)$ has non-negative drift, i.e. $\mu-\frac{\sigma^{2}}{2} \geq 0, \lambda_{x}$ is finite with probability one. If $\mu-\frac{\sigma^{2}}{2}>0$ then the expectation of $\lambda_{x}$ is finite.
} 
This condition says that the cost of expropriation and writing a new contract is smaller than the present value of the expected resource rent. It follows that (3.8) is a necessary and sufficient condition for expropriation of an infinitely long contract with positive probability.

Note that by (3.5) we must have $\frac{1}{\delta-\mu} \geq c$ (otherwise the lease rate would be negative). So if $k+c$ is large enough for (3.8) not to hold the government would never expropriate an infinitely long contract. It follows that under such circumstances such a contract would in fact be optimal. In the remainder of this paper we shall assume (3.8) is satisfied.

Under that assumption, whether expropriation occurs with certainty depends on the properties of the resource rent process:

Proposition 1. Assume (3.8) holds. Then optimal contracts either have finite maturity or they will be expropriated. Specifically, if $\mu-\frac{\sigma^{2}}{2}>0$, an infinitely long contract will be expropriated with probability one and the expected expropriation time is finite; if $\mu-\frac{\sigma^{2}}{2}=0$ and $\sigma>0$, expropriation occurs with probability one, but the expected expropriation time is infinite; if $\mu-\frac{\sigma^{2}}{2}<0$ and $\sigma>0$, expropriation will occur with positive probability, but not with certainty.

In other words, unless the resource rent process is deterministic with a nonpositive trend (i.e. $\sigma=0$ and $\mu \leq 0$ ) the government faces a problem of time inconsistency and must pay for this through higher transaction costs and lower surplus.

\section{The Deterministic Case}

We start by considering equilibrium in the case where the resource rent is deterministic and given by

$$
R_{t}=e^{\mu t}, \forall t \geq 0
$$

where we limit our attention to the non-trivial case when $\mu>0$. Note that by $(2.7)$ the lease rate for a contract that starts at time $t=0$ and expires or is expropriated at time $t=\tau$ is determined by

$$
\int_{0}^{\tau}\left(e^{\mu t}-l\right) e^{-\delta t} d t-c=0
$$

which implies

$$
l=\delta \frac{1-e^{-(\delta-\mu) \tau}}{1-e^{-\delta \tau}}\left(\frac{1}{\delta-\mu}-\frac{c}{1-e^{-(\delta-\mu) \tau}}\right)
$$


We begin with the result that neither infinitely long contracts nor expropriation will occur in equilibrium.

Proposition 2. When the resource rent is deterministic optimal contracts are of finite maturity and will not be expropriated.

Proof. We know from Section 3 that an optimal contract is of finite maturity or it will be expropriated. Suppose that it is optimal to enter into a contract (finitely or infinitely long) that will be expropriated at time $\tau$, where $\tau<\infty$ by Proposition 1 . The lease rate for the first such contract is given by (4.1). Consider an alternative first contract of length $T=\tau$ with the same lease rate. Clearly, such a similar contract with a shorter maturity will not be expropriated. Since the two contracts are effectively the same, except that the former involves costs of expropriation, the alternative contract is the better one. It follows that the optimal contract will not be expropriated and is of finite length.

The lease rate over a first contract period of length $T$ that will not be expropriated may be found from (4.1) with $\tau=T$. The discounted lease payments over the period are given by

$$
\int_{0}^{T} l e^{-\delta t} d t=\frac{1-e^{-(\delta-\mu) T}}{\delta-\mu}-c
$$

Given that the optimal contract maturity is $T^{*}$, the value of leasing the resource over its lifetime is given by

$$
V^{*}=\frac{1-e^{-(\delta-\mu) T^{*}}}{\delta-\mu}-c+e^{-(\delta-\mu) T^{*}} V^{*}
$$

or

$$
V^{*}=\frac{1}{\delta-\mu}-\frac{c}{1-e^{-(\delta-\mu) T^{*}}} .
$$

The value of the resource to the government is therefore given by the value of the resource less cumulative discounted transactions (contracting) costs. Note that the sum of discounted transactions costs declines with the contract length. The optimal contract maturity, $T^{*}$, must therefore be the longest such that the contract will not be expropriated.

\subsection{Optimal contract length}

Consider an initial contract of maturity $T \leq T^{*}$ starting at 0 with lease rate $l$ given by (4.1) for $\tau=T$ and assume that after this contract is terminated contracts of optimal maturity $T^{*}$ are offered. Let $V(t)$ be the optimal (remaining) value of this 
contract at time $t$. By the principle of optimality we must then have

$$
V(t)=\max \left\{l d t+V(t+d t) e^{-\delta d t},\left(V^{*}-k\right) e^{\mu t}\right\}
$$

for any $t \in(0, T)$ and infinitesimal $d t$. The first term inside the brackets is the return of the strategy of not expropriating in the interval $(t, t+d t)$. The second term is the return of expropriation at time $t$. The dynamic programming equation (4.4) is tantamount to $V$ satisfying the variational inequality

$$
\begin{gathered}
V^{\prime}(t)-\delta V(t)+l \leq 0 \\
V(t) \geq\left(V^{*}-k\right) e^{\mu t}
\end{gathered}
$$

with equality holding in the first line over an interval where no expropriation takes place.

It is easily seen that a solution to (4.5) is unique and is equal to the optimal value function $V$. The optimal time of expropriation - if such a time exists - is the first time equality obtains in the second line and strict inequality in the first.

Let

$$
v(t)=\int_{t}^{T} l e^{-\delta(s-t)} d s+e^{-\delta(T-t)} V^{*} e^{\mu T}
$$

be the value at time $t \in(0, T)$ of honouring the contract for the remainder of its lifetime. Suppose this is the optimal policy, so $v \equiv V$. It follows that for all $0 \leq t \leq T$ :

$$
v(t) \geq\left(V^{*}-k\right) e^{\mu t}
$$

where the inequality will be strict, except possibly at one point of indifference between expropriation and non-expropriation (this will be the case for the optimal contract maturity $T^{*}$ ). Conversely, suppose (4.7) holds for all $0 \leq t \leq T$ with strict inequality (except possibly at a point of indifference as before). It is easily seen that $v$ is a solution to the ordinary differential equation $v^{\prime}-\delta v+l=0$ so $v$ is a solution to $(4.5)$ and, hence, $v \equiv V$.

It follows that (4.7) is a necessary and sufficient condition for a contract of length $T \leq T^{*}$ not to be expropriated.

Let $f$ be the premium for letting the contract run to maturity rather than expropriating at $t$, viz.

$$
f(t)=v(t)-\left(V^{*}-k\right) e^{\mu t}
$$

Note that

$$
\int_{t}^{T} l e^{-\delta(s-t)} d s=\left(1-e^{-\delta(T-t)}\right) \frac{l}{\delta}
$$


which implies

$$
f(t)=\frac{l}{\delta}+A e^{\delta t}-B e^{\mu t},
$$

where $A=e^{-\delta T}\left(e^{\mu T} V^{*}-\frac{l}{\delta}\right)>0$ and $B=V^{*}-k>0$ are functions of $T$ and $T^{*}$ only. The condition (4.7) may therefore alternatively be written

$$
f(t)=\frac{l}{\delta}+A e^{\delta t}-B e^{\mu t} \geq 0
$$

The optimal first-period contract must be such that $\min _{t \leq T} f(t)=0$, since otherwise the government could make the contract longer and it would still be honoured.

Note that we have

$$
\begin{gathered}
f^{\prime}=\delta A e^{\delta t}-\mu B e^{\mu t} \\
f^{\prime \prime}=\delta^{2} A e^{\delta t}-\mu^{2} B e^{\mu t} .
\end{gathered}
$$

Observe that, if $\hat{t}$ is a point such that $f^{\prime}(\hat{t})=0$ then, since $\delta>\mu$, it holds that $f^{\prime}(t) \gtrless 0$ for all $t \gtrless \hat{t}$. It follows that, if such a $\hat{t}$ exists, then it is the unique minimand.

We have that $f^{\prime}(0)<0$. To see this, assume the contrary, i.e. that $f^{\prime}(0) \geq 0$ . Then, since $f^{\prime \prime}(t)>0$ whenever $f^{\prime}(t) \geq 0, f$ is strictly increasing everywhere on $(0, T]$. Moreover, since $f(0) \geq 0$ (by the optimality of $T$ ), $f(t)>0$ for all $0<t \leq T$. Since $\frac{d}{d T} f(0)>0$ (which we obtain by substituting (4.6) and (4.2) in (4.8) and differentiating), it follows that the contract could be improved by extending its maturity, contradicting the assumption that $T$ is the optimal length of the contract.

Furthermore, we have that $f^{\prime}(T)>0$. If this were not the case, $f^{\prime}(t)$ would have to be strictly negative for all $t$ (again, since $f^{\prime \prime}(t)>0$ whenever $f^{\prime}(t) \geq 0$ ) so $f(t) \geq f(T)=k e^{\mu T}>0$ for all $t$ and the contract could be improved by extending its maturity. We conclude that for a contract to be of optimal length, there is a unique $\hat{t}=\arg \min _{t \leq T} f(t) \in(0, T)$.

We summarise the above discussion in the following Proposition.

Proposition 3. The optimal contract is uniquely determined by the conditions

$$
\begin{gathered}
f^{\prime}(\hat{t})=0, \\
f(\hat{t})=0,
\end{gathered}
$$

where $f$ is defined in (4.9), $T=T^{*}, V^{*}$ is given by (4.3) and $l$ is given by (4.1) with $\tau=T^{*}$.

Figure 4.1 shows $f$ for three different values of $T$ given the baseline set of parameters $(\mu=0.02, \delta=0.1, k=1, c=0.5)$. The top curve shows $f$ for $T=18$. In this 


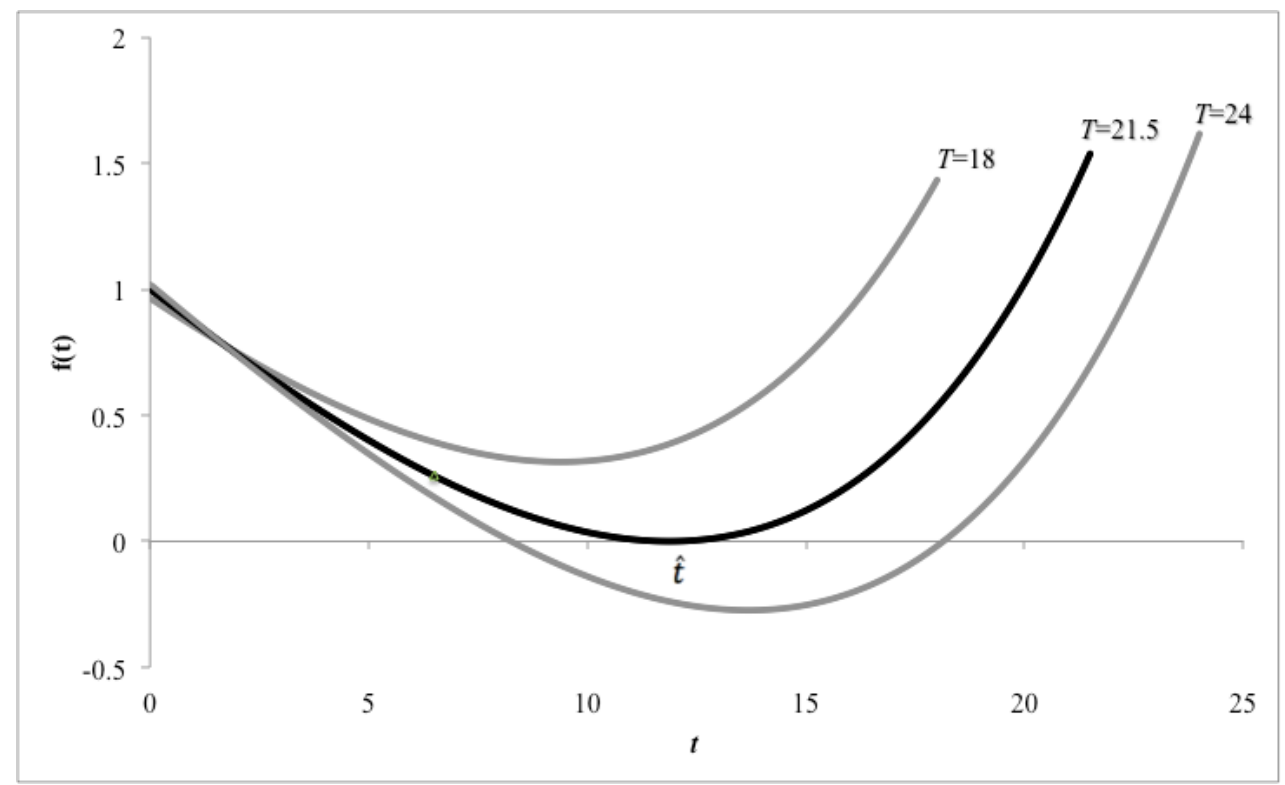

Figure 4.1: Premium for letting contract run to maturity

case the premium of letting the contract run to maturity is always positive so this contract will not be expropriated. It can, however, be improved upon by selecting a longer contract. The bottom curve shows $f$ for $T=24$. In this case, when $t$ goes beyond 8 , the premium turns negative and so the contract will be expropriated at this point. The middle curve, with $T \doteq 21.5$, corresponds to the longest contract that has a non-negative premium of not expropriating over its lifetime. This is the optimal contract. In this case the contract can be fine tuned such that the premium is exactly zero at its lowest point and the contract is upheld.

All the curves are U-shaped. There is no gain to expropriation in the beginning when the contract is (ex ante) optimal. Around the middle of the contract period expropriation becomes more tempting since the value of the resource (which is higher by now) can be cashed in. After this point has been passed expropriation becomes too costly in relation to the time remaining to expiration.

Note that a slight increase in the contract length beyond the optimum would imply that the premium of honouring the contract shown in Figure 4.1 will turn negative slightly before $\hat{t}$. Effectively, the lifetime of the contract would then be approximately halved, dropping from $T \doteq 21.5$ to $\hat{t} \doteq 11.9$ as the contract is expropriated. This implies a discrete drop in the value of the contract to a value corresponding to that of a contract of length $\hat{t}$ less the discounted cost of expropriation. 
Table 2: Comparative statics in deterministic case (baseline: $\mu=0.02, \delta=0.1$, $k=1, c=0.5)$.

\begin{tabular}{|c|c|c|c|c|}
\hline & $T^{*}$ & $\hat{t}$ & $V^{*}$ & $l^{*}$ \\
\hline \hline Baseline & 21.50 & 11.88 & 11.89 & 1.10 \\
\hline \hline$k=0.5$ & 14.91 & 8.00 & 11.78 & 1.06 \\
\hline$k=2.0$ & 31.89 & 18.35 & 11.96 & 1.15 \\
\hline \hline$c=0.25$ & 21.20 & 11.70 & 12.19 & 1.13 \\
\hline$c=1.00$ & 22.12 & 12.25 & 11.29 & 1.05 \\
\hline \hline$\delta=0.05$ & 20.61 & 10.48 & 32.25 & 1.16 \\
\hline$\delta=0.20$ & 24.94 & 16.08 & 5.05 & 1.01 \\
\hline \hline$\mu=0.01$ & 31.39 & 18.78 & 10.58 & 1.04 \\
\hline$\mu=0.04$ & 14.92 & 7.64 & 15.82 & 1.21 \\
\hline
\end{tabular}

\subsection{Comparative statics}

Using the condition (4.10) to solve for $\hat{t}$, we get

$$
\hat{t}=\frac{1}{\delta-\mu} \ln \frac{\mu B}{\delta A}
$$

Inserting into (4.11) and simplifying gives

$$
\frac{l^{*}}{\delta}-\frac{\delta-\mu}{\delta}\left(\frac{\mu}{\delta}\right)^{\frac{\mu}{\delta-\mu}} \frac{B^{\frac{\delta}{\delta-\mu}}}{A^{\frac{\mu}{\delta-\mu}}}=0,
$$

where $l^{*}$ is the lease rate in the optimal contract. Note that $T^{*}$ enters into this equation via $A$. Using equation (4.1) with $\tau=T^{*}$ to derive an expression for $l^{*}$ in terms of $T^{*}$ and the expression (4.3) for $V^{*}$ allows in principle to solve for $\hat{t}$ and $T^{*}$. The resulting equations do however not allow for an analytical solution and so we have resorted to numerical solutions to study comparative statics.

The top row of the Table 2 shows the baseline solution. The value of the resource to the government, $V^{*} \doteq 11.89$, and the corresponding lease rate, $l^{*} \doteq 1.10$, may be compared to the values with perfect commitment (i.e. when $k=\infty$ ) which are given by $V^{\infty}=12.00$ and $l^{\infty}=1.20$, respectively (cf. (3.4) and (3.5)).

In subsequent rows we vary the parameters, respectively halving and doubling each from the baseline value.

A higher cost of expropriation involves a longer equilibrium contract, a higher lease rate and a larger (net) value of the resource. While expropriation never occurs in equilibrium the cost of expropriation affects the incentive to expropriate; specifically, a higher cost reduces the incentive. Therefore, a higher cost of expropriation makes it possible to enter into a longer contract and increases the net value 
of the resource by virtue of saving contracting costs. With these parameter values, a doubling of the expropriation cost implies an increase in optimal maturity by half.

A higher cost of contracting also involves a longer equilibrium contract, but a lower lease rate and a smaller value of the resource. The contracting cost is borne by the leaseholder so a higher cost requires a lower lease rate (for a given contract length). A lower lease rate implies a smaller value of the resource. A smaller value of the resource makes it less tempting to expropriate, making longer contracts possible. Longer contracts counteract the direct impact of higher contracting costs and hence mitigate the overall reduction in resource value. The impact of contracting cost is, however, small; a doubling increases optimal maturity by only 3 per cent.

A higher discount rate has a similar effect as a higher contracting cost. The present value of the flow of resource rent over a given contract period is lower with a higher discount rate. Hence, both lease rate and resource value are reduced. Again, the smaller resource value diminishes the incentive to expropriate, leading to a longer contract. A doubling of the discount rate increases optimal maturity by 16 per cent.

A higher expected growth rate of resource rent works in a similar fashion as a higher discount rate, but with the opposite direction and a relatively strong impact. Both lease rate and resource value are increased while the expropriation incentive is reduced, leading to a shorter equilbrium contract. A doubling of the growth rate reduces optimal maturity by a third.

\subsection{Expropriation boundary}

It is useful, especially in relation to the stochastic version of the model, to study the deterministic case from a different angle, viz. that of a 'critical' value of resource rent at which expropriation takes place.

Keep $V^{*}$ fixed and also - for the time being - the lease rate $l$. Define $\bar{r}(t)$ as the critical resource rent which demarcates profitable and non-profitable expropriation, i.e. if we are at the point $(t, \bar{r}(t))$ we have

$$
v(t)=\bar{r}(t)\left(V^{*}-k\right)
$$

where on the left we have the payoff of continuation until the end and on the right the payoff of expropriation. Using the property that $r(T)=r(t) e^{\mu(T-t)}$, this is equivalent to

$$
\bar{r}(t)=\frac{l}{\delta} \frac{\left(1-e^{-\delta(T-t)}\right)\left(V^{*}-k\right)}{\left(1-e^{-(\delta-\mu)(T-t)} V^{*}\right)-k} .
$$

Note that as $t$ approaches $t^{c}=T+\frac{1}{\delta-\mu} \log \left(1-\frac{k}{V^{*}}\right)<T$ from the left the denom- 


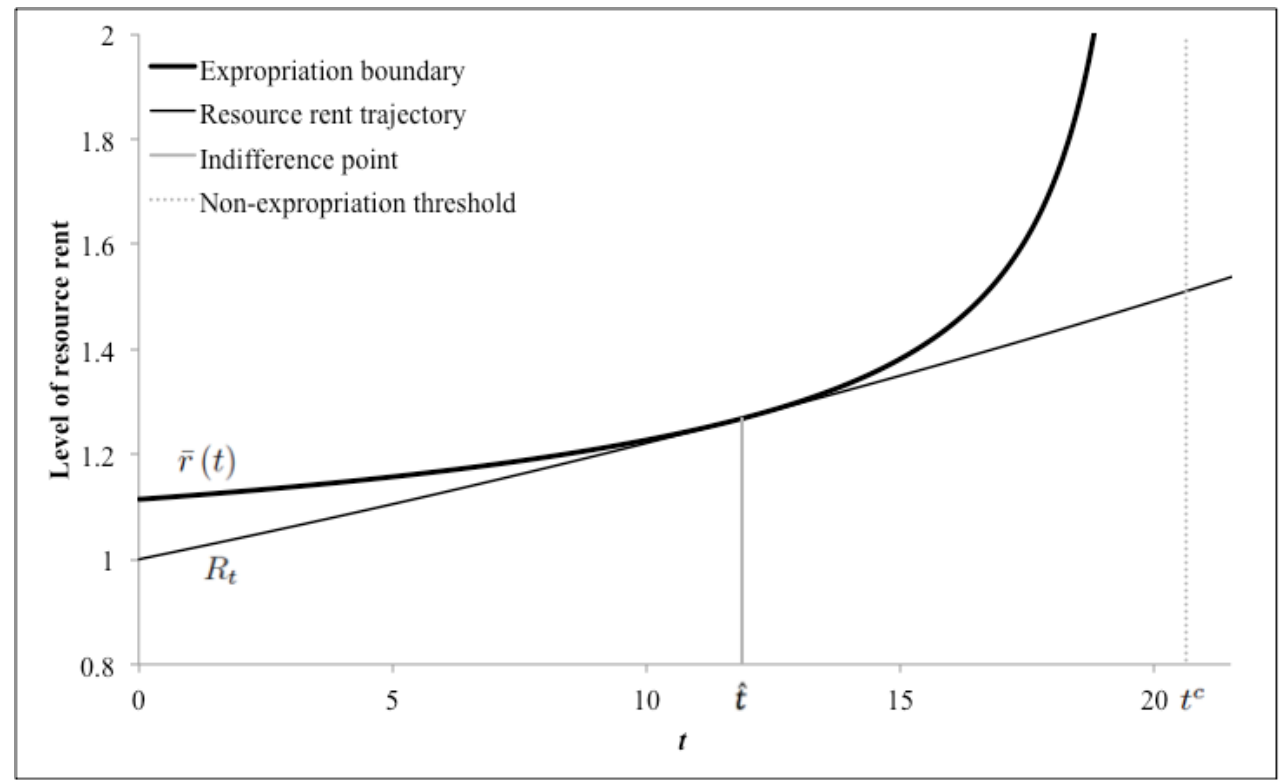

Figure 4.2: Expropriation boundary and resource rent in deterministic case

inator approaches zero and so $\bar{r}(t) \rightarrow \infty$. After this point it is not profitable to expropriate, regardless of the level of the resource rent.

Figure 4.2 shows the expropriation boundary, computed from (4.12) with the same parameter values as in the previous subsection and with $T$ equal to the optimal value for these parameters (see Table 2 for numerical values). The figure also shows the resource rent trajectory $R_{t}=e^{\mu t}$ which touches the critical boundary tangentially at $\hat{t}$, where there is indifference between expropriating or not. With a shorter contract the expropriation boundary would shift upwards and would then lie strictly above $R_{t}$ for all $t$. Similarly to our previous analysis, this indicates that the contract can be made longer without being expropriated. Conversely, were the contract to be made longer, the expropriation boundary would shift downwards, and expropriation would occur at the point where the resource rent trajectory cross the expropriation boundary.

Figure 4.2 provides some intuitive insight into the question of why the optimal time horizon is shortened when stochasticity is added, as we shall see below. Consider a contract that is optimal in the deterministic case and assume that we add some stochasticity to the resource rent process (i.e. $\sigma>0$ ). The expropriation boundary will then be shifted up due to the addition of a new cost term, viz. the option value of expropriation, but it will have the same properties as in the figure. In particular, it will be relatively flat to the left of $\hat{t}$, where the resource rent touches the expropriation boundary in the deterministic case. Assuming the critical boundary will not shift much, the resource rent trajectory will make expropriation 
very likely - in fact there will be close to a 50 per cent chance of expropriation. To avoid considerable expected expropriation costs it would then make sense to shorten the time horizon, shifting the expropriation boundary above the resource rent path. The effective contract lifetime (i.e. accounting for the possibility of expropriation) will be similar as in the deterministic contract so the lease rate will not be much affected. However, expropriation becomes less likely and the related costs are lower and hence the value of the resource is higher than if the deterministic contract were used.

\section{The General Case}

We now consider the general case where the resource rent $R$ is a geometric Brownian motion as in (2.1) with positive volatility $\sigma>0$.

\subsection{Optimal expropriation strategy}

In this section we characterise the optimal expropriation strategy proceeding along similar lines as in Section 4.1. Consider an initial contract of maturity $T \in(0, \infty)$ starting at $t=0$. We first take the lease rate $l>0$ as given and assume that after this contract expires contracts of the same maturity and value are offered. If expropriation has not occurred by time $t$, let $v(t, r)$ be the optimal (remaining) value of this contract at resource rent $R_{t}=r$. In particular, $v(0,1)=V$ and $v(T, r)=r V$, where $V$ is given by $(2.11)$.

By the principle of optimality, we must then have

$$
v\left(t, R_{t}\right)=\max \left\{l d t+E\left[v\left(t+d t, R_{t+d t}\right) e^{-\delta d t} \mid R_{t}\right],(V-k) R_{t}\right\}
$$

for any $t \in(0, T)$ and infinitesimal $d t$. The first term inside the brackets is the expected return of the strategy of not expropriating in the interval $(t, t+d t)$. The second term is the return of expropriation at time $t$. The optimal action (expropriate, or wait and reconsider at time $t+d t$ ) is decided so as to maximise the expected return. By Ito's rule, the dynamic-programming equation (5.1) is equivalent to $v$ satisfying the variational inequality

$$
\begin{gathered}
v_{t}+\mu r v_{r}+\frac{\sigma^{2}}{2} r^{2} v_{r r}+l \leq \delta v(t), \\
v(t, r) \geq(V-k) e^{\mu t} .
\end{gathered}
$$

Over the 'continuation' area of the $(t, r)$-plane where no expropriation takes place the first relation holds with equality and the second with strict inequality. At the 
time of expropriation - if this exists - the first relation holds with strict inequality and the second with equality.

The problem of determining $v(t, r)$ is analytically analogous to the pricing of an American call option on a dividend-paying asset with underlying asset value $V R_{t}$, dividend flow $l$, maturity $T$ and a strike price $k$ (see e.g. Duffie, 2001, and Karatzas and Shreve, 1991). The difference is that if the option is exercised before maturity, so $\tau<T$, then the payment is not $V R_{\tau}-k$, as would be the case in a standard American call option, but rather $(V-k) R_{\tau}$. If the option is held to maturity the terminal payment is $V R_{T}$ instead of $\max \left\{V R_{T}-k, 0\right\}$ in the standard case where the strike price is fixed.

One can therefore formulate the problem as follows: find functions $u(t, r)$ and function $\bar{r}(t)$ such that

$$
\begin{gathered}
\delta u=\mu r v_{r}+\frac{1}{2} \sigma^{2} r^{2} u_{r r}+u_{t}+l, \text { for } 0<t<T, 0<r<\bar{r}(t), \\
u(t, r)=r[V-k], \text { for } 0<t<T, r \geqslant \bar{r}(t), \\
u_{r}(t, r)=V-k, \text { for } 0<t<T, r \geqslant \bar{r}(t), \\
u(T, r)=r V, \text { for } r>0 .
\end{gathered}
$$

The third equation is derived from the so-called 'smooth fit' condition at the expropriation boundary $\bar{r}(t)$. The function $u$ must be twice continuously differentiable in the area below $\bar{r}$, i.e. for $(t, r)$ such that $0<t<T$ and $0<r<\bar{r}(t)$.

Given a solution, $u$, to the above problem, it can - by an application of Ito's rule - be shown to be unique and equal to $v(t, r)$. The expropriation boundary $\bar{r}$ then also provides the optimal stopping strategy, i.e. it is optimal to expropriate the first time the resource rent process hits the boundary:

$$
\tau=\inf \left\{t \geq 0 ; R_{t} \geq \bar{r}(t)\right\}
$$

In general, explicit value functions and exercise strategies for American call options do not exist, necessitating the use of numerical methods. So is the case in the problem at hand, even before the endogeneity of the dividend flow (lease rate) $l$ and the payoff $(V)$ is taken into account. We return to this below.

\section{$5.2 \quad$ Infinitely long contracts}

In the case of an infinitely long contract - i.e. when the resource is sold - the partial differential equation in (5.3) reduces to an ordinary differential equation. 
Furthermore, the expropriation boundary becomes a constant $\bar{r}$. In this case it is possible to obtain an analytical solution for the optimal expropriation strategy for given values of $V$ and $l$ by standard methods (e.g. Dixit and Pindyck, 1994). Taking the endogeneity of $V$ and $l$ into account results in a set of non-linear equations which do not admit closed-form solution, but are easily solved numerically. See Appendix A for details.

With the baseline set of parameters $(\mu=0.02, \delta=0.1, k=1, c=0.5, \sigma=0.1)$, the optimal expropriation boundary is found to be $\bar{r} \doteq 1.38$, so it is optimal to expropriate the resource when the resource rent first exceeds the initial value by 38 per cent. This strategy results in resource value $V \doteq 10.57$. Recall from Section 3 that with $\mu-\frac{\sigma^{2}}{2} \geq 0$ expropriation will occur with probability one and this is the case here. Furthermore, when $\mu-\frac{\sigma^{2}}{2}>0$ the expected time to expropriation is finite and given by (A.8). With the current parameter values the expected time to expropriation, or effective lifetime of the contract, is $E \tau \doteq 21.60$.

\subsection{A lower bound for the expropriation boundary}

Given values for $l$ and $V$, a lower bound can be derived for the expropriation boundary $\bar{r}$ in much the same fashion as the exact boundary was derived in the deterministic case. Suppose that, for a given lease rate $l$, it is optimal to expropriate at $(t, \bar{r}(t))$. Then the payoff associated with expropriation at this point has to be at least as big as that of allowing the contract to run to maturity, so

$$
\bar{r}(V-k) \geq E_{t, \bar{r}}\left[\int_{t}^{T} e^{-\delta(s-t)} l d s+R_{T} e^{-\delta(T-t)} V\right],
$$

where $E_{t, \bar{r}}$ denotes expectation taken at time $t$ conditional on $R_{t}=\bar{r}(t)$. Since $E_{t, \bar{r}}\left[R_{T}\right]=\bar{r}(t) e^{\mu(T-t)}$ we can rewrite this as

$$
\bar{r}(t)\left[\left(1-e^{-\delta(T-t)}\right) V-k\right] \geq \frac{l}{\delta}\left(1-e^{-\delta(T-t)}\right) .
$$

Let

$$
t^{c}=T+\frac{1}{\delta-\mu} \ln \left(1-\frac{k}{V}\right),
$$

where we note that $t^{c}<T$.

For $t<t^{c},\left(1-e^{-\delta(T-t)}\right) V-k$ is positive and finite and (5.4) implies

$$
\bar{r}(t) \geq \frac{l}{\delta} \frac{1-e^{-\delta(T-t)}}{\left(1-e^{-(\delta-\mu)(T-t)}\right) V-k} .
$$


Hence, $\bar{r}(t)>0$ for $t<t^{c}$. As $t \rightarrow t^{c}$ the denominator in (5.6) tends to zero while the numerator is bounded away from zero, so the lower bound for $\bar{r}(t)$, and hence $\bar{r}(t)$ itself, will tend to infinity.

For $t \geq t^{c}$, we have $\left(1-e^{-(\delta-\mu)(T-t)}\right) V-k<0$, so the opposite inequality to (5.4) holds and it cannot pay to expropriate the contract at any level of the resource rent. Hence, the expropriation boundary is infinite for $t \geq t^{c}$ and contracts are upheld if they survive up to this point.

\subsection{Characterisation of contracts}

In the characterisation of the expropriation strategy above we assumed the lease rate $l$ to be given and fixed. The lease rate is, however, endogenous and determined by the zero-profit condition (2.7), which implies the expression (2.9). Note that in the present setting, equilibrium (cf. the definition in Section 2.4) is given by a contract of maturity, $T^{*}$, that maximises $V$, an expropriation boundary, $\bar{r}^{*}(2.11)$, which provides the (time consistent) optimal expropriation strategy $\tau^{*}=\inf \left\{t \geq 0 ; R_{t} \geq \bar{r}^{*}(t)\right\}$, and a lease rate, $l^{*}$, determined by the zero-profit condition (2.7) with $\tau=\tau^{*}$.

It follows directly from the properties of the expropriation boundary that sufficiently short contracts will never be expropriated. Specifically, suppose a contract of maturity $T$ is never expropriated. Its value, $V$, is then given by the same expression as in the deterministic case, viz. (4.3). From (5.5), it follows that if $T$ satisfies $T<\frac{-1}{\delta-\mu} \ln \left(1-\frac{k}{V}\right)$ the contract will not be expropriated. It is easily seen that this will be true for any contract of maturity $T<\frac{-1}{\delta-\mu} \ln (1-(\delta-\mu)(k+c))$.

We conjecture that contracts with no expropriation are not optimal. Intuitively, by extending a contract of length $T^{c}=\frac{-1}{\delta-\mu} \ln (1-(\delta-\mu)(k+c))$ by a little bit, there is a gain due to costs of entering into future contracts being pushed out in time; there is also a loss due to the possibility of expropriation - this is, however, very unlikely since the expropriation boundary goes to infinity for contract lengths close to $T^{c}$. Alternatively, if the value function is smooth (continuously differentiable) in $T$, then, since $V$ is increasing in $T$ for $T<T^{c}$, it must hold that $T^{*}>T^{c}$. If so, the equilibrium contract involves expropriation.

We further conjecture that for finite (but positive) values of $k$ an infinitely long contract cannot be optimal. As demonstrated above, an infinitely long contract will surely be expropriated. While a shorter contract may involve more frequent contract renewals, the probability and cost of expropriation are reduced. If so, equilibrium contracts are finite.

We have not been able to confirm these conjectures analytically, but below we 
demonstrate numerically that they are true for reasonable parameter values.

\subsection{Numerical results}

As noted above, the partial differential equation problem (5.3) is not amenable to analytical solution so we must rely on numerical methods. We employ a common approach in this type of problem: value function iteration with approximation of the geometric Brownian motion by a simple geometric random walk. The problem has an extra layer of complexity relative to standard option-pricing problems in that the lease rate and payoff upon expropriation or maturity of the contract are endogenous. It is therefore necessary to start off with a guess at the equilibrium lease rate and resource value. Given these initial values, we derive the optimal expropriation strategy by backward induction, which allows computation of new values for the lease rate and resource value. The iteration is continued until the resource value has converged, i.e. the change in resource value between iterations is sufficiently small. Details of the numerical algorithm are given in Appendix B. ${ }^{28}$

\section{Baseline scenario}

Figure 5.1 is the stochastic counterpart of Figure 4.2. The expropriation boundary is shown for $T=21.5$ (which is the optimal maturity in the deterministic case). The figure also shows two examples of simulated resource rent paths, where one path leads to expropriation (at $t \doteq 11$ ) and the other allows the contract to run to maturity without expropriation. There is in fact a high probability of expropriation in this case, viz. 61 per cent, implying substantial transaction costs and suboptimality of contracts this long.

Figure 5.2 shows the resource value, $V$, and the lease rate, $l$, for different values of $T$. The resource value increases with contract maturity up to a maximum at $T \doteq 7$ whereafter it decreases and approaches the value of an infinitely long contract (cf. Section 5.2). The lease rate follows a similar pattern, but reaches maximum for a longer contract, at $T \doteq 8$.

The relationship between contract maturity, on the one hand, and resource value and lease rate, on the other, is driven by the probability of expropriation and lifetime of the contract. Figure 5.3 shows expected lifetime, $E \tau$, and the probability of expropriation, $\operatorname{Pr}\{\tau<T\}$ for the same setting as in Figure 5.2. There is no

\footnotetext{
${ }^{28}$ Due to discretisation and a finite number of simulated resource rent paths there is a small amount of variation in the numerical results. This implies that some caution must be exercised in the interpretation of results; in particular, when the probability of expropriation is small the numerical error is large as a proportion of the estimated probability. For purposes of presentation, in the figures below the results have been smoothed using the Savitzky-Golay filter in MATLAB.
} 


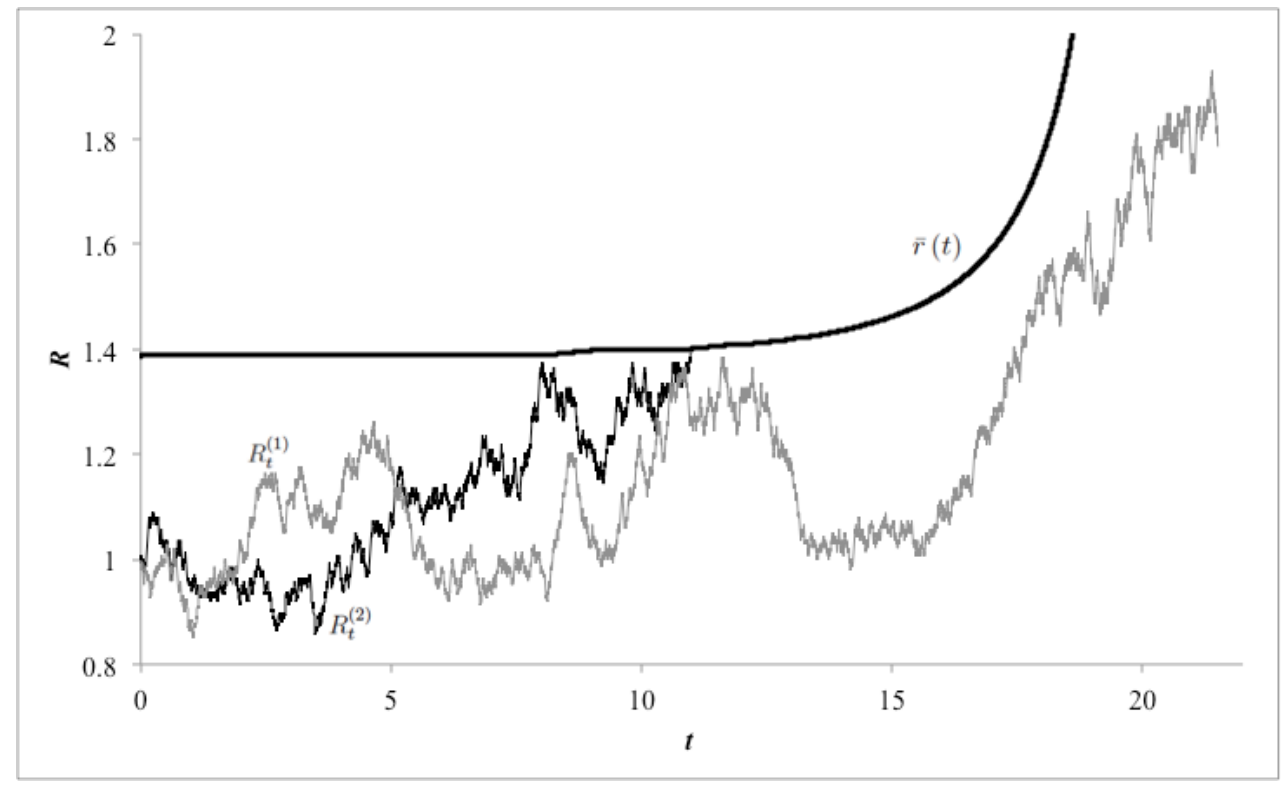

Figure 5.1: Expropriation boundary, $\bar{r}(t)$, and two simulated resource rent paths, $R_{t}^{(i)}, i=1,2(\mu=0.02, \delta=0.1, k=1, c=0.5, \sigma=0.1, T=21.5)$.

expropriation at short contract lengths and hence contract lifetime is equal to contract maturity. ${ }^{29}$ As the contract length approaches the optimum, expropriation will take place, albeit at low probability; at optimum, the expropriation probability is 3 per cent and expected contract lifetime is $E \tau \doteq 6.8$ or 98 per cent of contract length. For longer contracts, the expropriation probability increases and approaches 1. With expropriation, expected lifetime drops below, and eventually becomes only a fraction of, maturity.

The reason that contract lifetime increases with maturity, but at a lower rate, is that with longer contracts more resource rent paths lead to expropriation. Along paths that rise quickly expropriation will occur with both short and long contracts. However, along paths that initially remain low but eventually turn and rise to high levels, expropriation will not occur for contracts with short maturity, but for longer maturities it will. As contract maturity becomes very long, expropriation will occur along almost all paths and expected contract lifetime will approach the theoretical limit derived in Section $5.2(E \tau \doteq 21.60$ for baseline parameter values).

For the lease rate, a longer maturity therefore involves two effects that pull in opposite directions: a higher expected lifetime tends to increase the lease rate, whereas

${ }^{29}$ With the baseline parameter values there will be no expropriation for contracts shorter than $T \doteq 1.6$. The shortest contract maturity in the numerical results is $T=2$ so in the theoretical model there would, in fact, be some expropriation at all values of $T$ considered, but with very low probability. In the discretisation there is an upper limit on how fast the geometric random walk can approach the expropriation boundary, so $T$ must exceed a certain limit $-T=5$ in the baseline scenario - before expropriation can occur. 


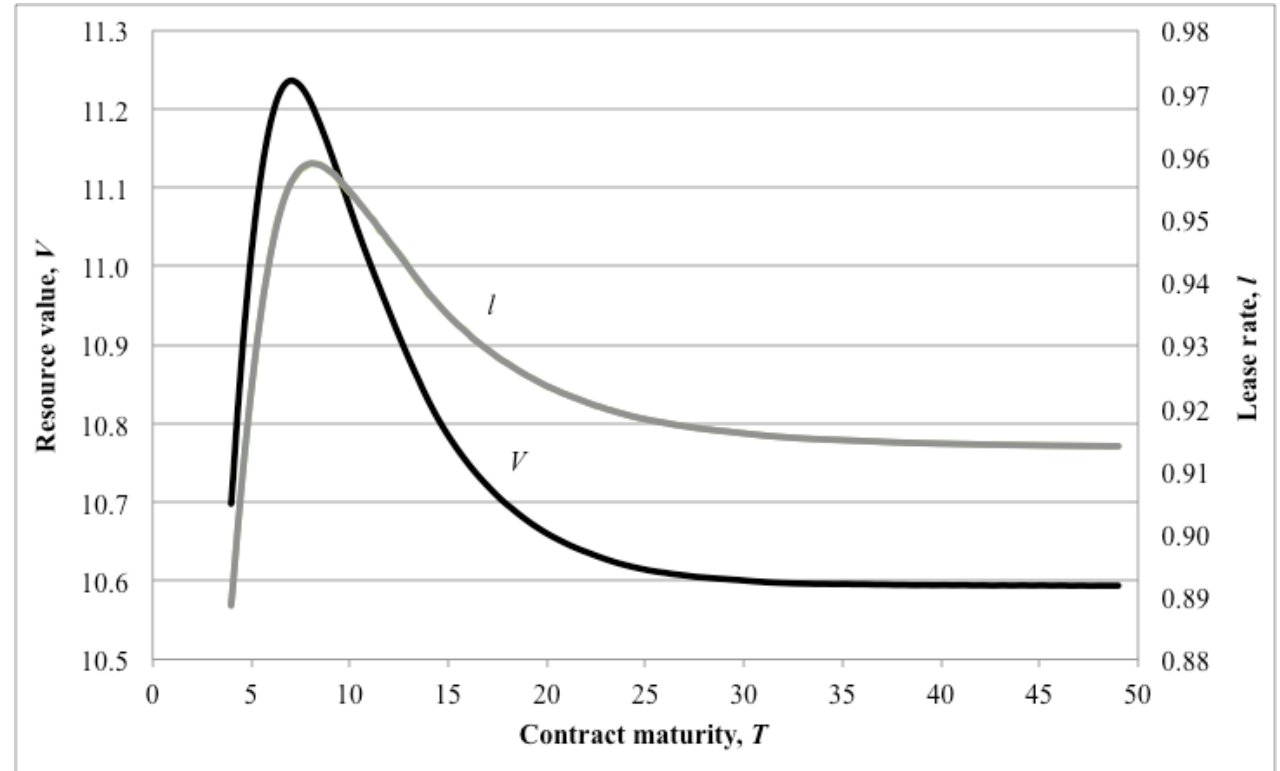

Figure 5.2: Resource value and lease rate, baseline scenario $(\mu=0.02, \delta=0.1$, $k=1, c=0.5, \sigma=0.1)$.

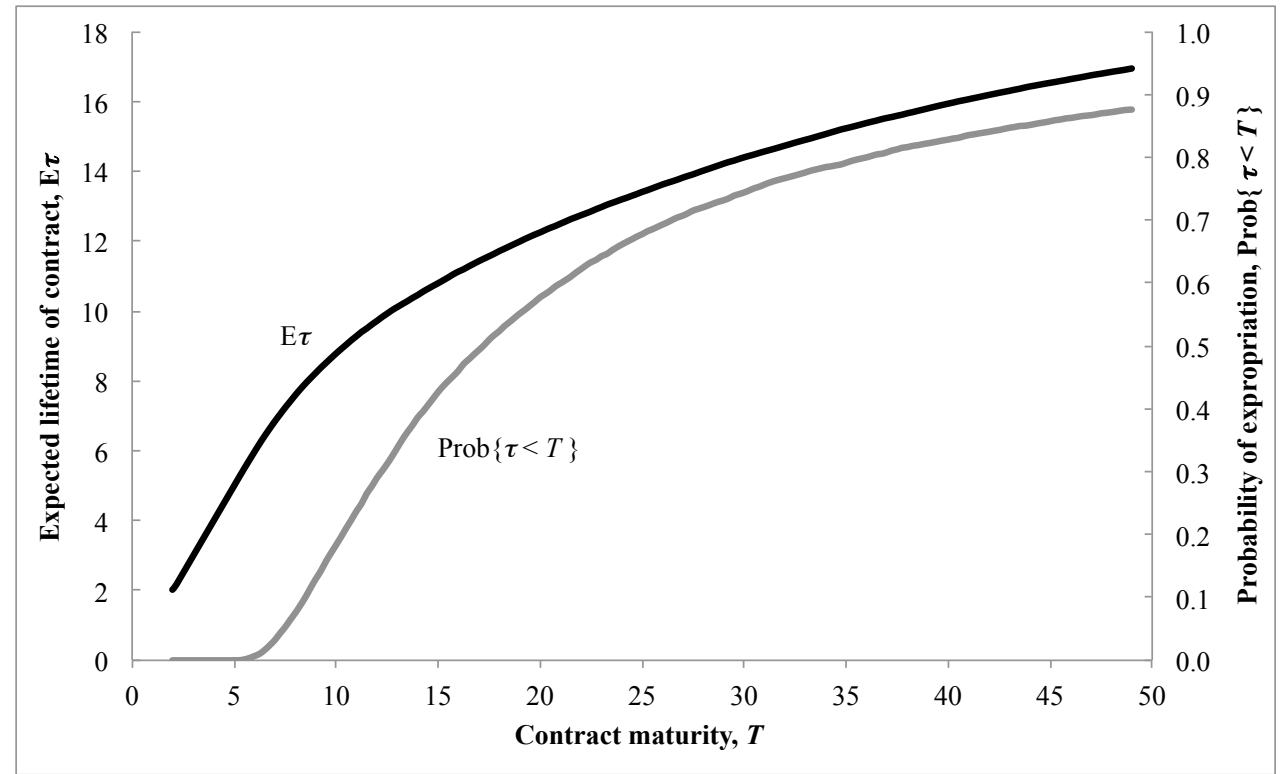

Figure 5.3: Expected lifetime of contract and probability of expropriation, baseline scenario $(\mu=0.02, \delta=0.1, k=1, c=0.5, \sigma=0.1)$. 


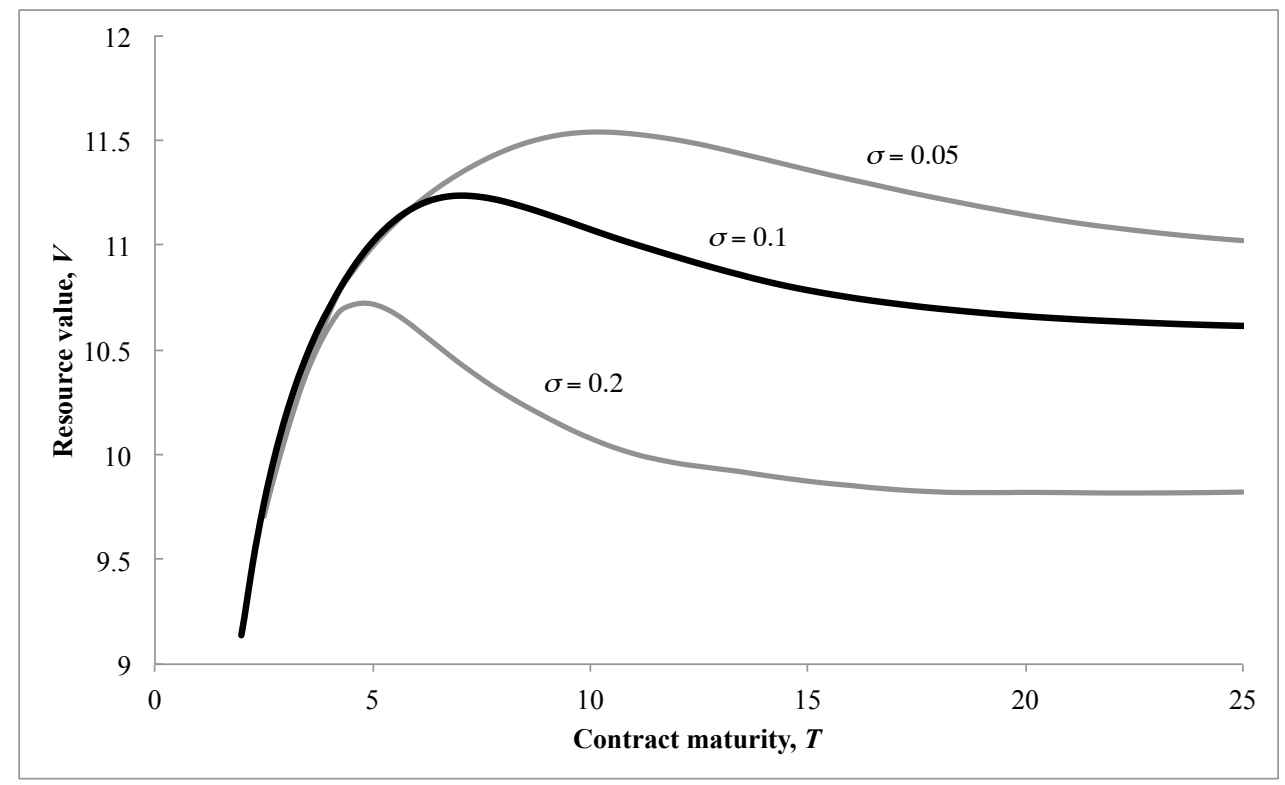

Figure 5.4: Resource value for alternative values of volatility $(\mu=0.02, \delta=0.1$, $k=1, c=0.5)$.

a lower expected return, due to a higher incidence of resource rent paths involving expropriation and elimination of upside gains, tends to reduce it; for sufficiently long maturities the latter effect dominates and hence the lease rate falls. For the resource value, the same effects are at play, but in addition there is the negative impact of expropriation costs; consequently, the resource value reaches its maximum before the lease rate.

\section{Comparative statics}

Figure 5.4 shows the resource value as a function of contract maturity for alternative volatities of the resource rent. A larger volatility leads to a reduction in resource value and a shorter optimal contract maturity. For a given contract, a larger volatility results in a higher incidence of high resource rents that trigger expropriation. To avoid excessive expropriation costs the optimal contract is shortened; nevertheless, both expropriation and transaction costs rise, reducing (net) resource value.

Table 3 summarises the implications of changes in volatility, as well as other parameters, on key variables, by, respectively, halving and doubling each parameter from the baseline value. ${ }^{30}$

\footnotetext{
${ }^{30}$ For $k, c$, and $\delta$, the comparative statics computations are performed on the same set of simulated resource rent paths as in the baseline solution. For $\sigma$ and $\mu$ a different set of simulated paths must necessarily be generated for each parameter value; this introduces an additional source of variation in outcomes in these cases. This affects, in particular, estimates of the probability of expropriation as $\sigma$ and $\mu$ are varied; the order of magnitude is the same, but we are reluctant to place too much weight on the precise numerical values.
} 
Table 3: Comparative statics in general case (baseline: $\mu=0.02, \delta=0.1, k=1$, $c=0.5, \sigma=0.1)$.

\begin{tabular}{|c|c|c|c||c|c|}
\hline & $T^{*}$ & $E \tau^{*}$ & $\operatorname{Pr}\left\{\tau^{*}<T^{*}\right\}$ & $V^{*}$ & $l^{*}$ \\
\hline \hline Baseline & 7.00 & 6.85 & $3.25 \%$ & 11.23 & 0.96 \\
\hline \hline$\sigma=0.05$ & 10.00 & 9.83 & $2.73 \%$ & 11.54 & 1.00 \\
\hline$\sigma=0.20$ & 4.75 & 4.67 & $2.38 \%$ & 10.73 & 0.90 \\
\hline \hline$k=0.5$ & 5.00 & 4.71 & $8.54 \%$ & 10.73 & 0.90 \\
\hline$k=2.0$ & 10.50 & 10.44 & $0.89 \%$ & 11.61 & 1.01 \\
\hline \hline$c=0.25$ & 6.00 & 5.96 & $1.04 \%$ & 11.83 & 1.00 \\
\hline$c=1.00$ & 8.50 & 8.10 & $7.07 \%$ & 10.21 & 0.88 \\
\hline \hline$\delta=0.05$ & 6.25 & 6.14 & $2.64 \%$ & 30.21 & 0.96 \\
\hline$\delta=0.20$ & 8.50 & 7.62 & $15.08 \%$ & 4.88 & 0.94 \\
\hline \hline$\mu=0.01$ & 7.25 & 7.10 & $3.04 \%$ & 9.99 & 0.93 \\
\hline$\mu=0.04$ & 6.50 & 6.36 & $3.27 \%$ & 15.00 & 1.01 \\
\hline
\end{tabular}

As we would expect, the optimal contract maturity is increasing in cost of expropriation, transaction cost and discount rate, but decreasing in resource rent growth rate. However, transaction cost, discount rate and growth rate have a relatively small impact on the optimal maturity; this is mainly determined by volatility and expropriation cost.

The probability of expropriation is mainly determined by the expropriation and transaction cost, as well as the discount rate. Naturally, a higher cost of expropriation leads to less expropriation. A higher transaction cost provides an incentive for longer contracts with the consequence of more frequent expropriation. A higher discount rate has a similar effect.

The results may be compared to those in the deterministic case given in Table 2. The direction of change for the variables common to both cases is the same. Moreover, the relative changes are of the same order of magnitude, except for the resource rent growth rate, where the impact on contract maturity is large in the deterministic case but small in the stochastic. In the deterministic case it turns out that a condition for optimality is that the government, mid-way through the contract period, is indifferent between expropriation and letting the contract run to maturity (cf. (4.11)). The incentive to expropriate therefore depends on the value of the contract for the remainder of the period, which is strongly affected by a change in the growth rate through the compounding effect. This property does not carry over to the stochastic case, where the solution is based on a marginal principle of optimality (cf. (5.1)); at each moment the comparison is between expropriation and continuation for a short period for which the growth rate has little impact. 
The computations underlying the comparatic static exercise also yield a robustness check of our results. In particular, for all parameter combinations there exists a solution and it has similar properties as in the baseline scenario. Furthermore, the comparative static exercise indicates that marginal effects are monotone; as a further test of this we have solved the model for a broad range of values of $k$ and $\sigma$ - the two parameters of most interest - confirming these results.

\section{Conclusion}

We have shown that the possibility of expropriation leads governments to limit the length of contracts for exploiting renewable resources. When resource rent is deterministic the contract length can be set so as to exactly avoid the imperative to expropriate. In the more realistic case of stochastic resource rent the government cannot avoid expropriation altogether, but its probability is reduced by a shorter contract length and in optimal contracts the probability of expropriation is low. We have also shown that higher costs of expropriation make longer contracts more attractive and increase the net value of the resource. Increased variability of resource rent, however, makes situations where the government finds itself unable to resist the temptation to expropriate more likely and reduces the net value of the resource.

Our present work can be extended in several different directions. One such direction arises from inefficiency in the use of a renewable resource - e.g. overharvesting of a fishery or insufficient maintenance of a hydro power plant as the end of a concession period draws near - that may arise from exploitation contracts of finite length. This dimension is absent here. In reality, however, the length of a contract will affect the incentives for 'bad' behaviour by the firm that is given the right to exploit the resource: the shorter the contract the stronger the incentives for mismanagement of the resource and the lower the resulting net resource value. ${ }^{31}$ This has implications for incentives to expropriate and the optimal design of contracts, including contract length. ${ }^{32}$

\footnotetext{
${ }^{31}$ Costello and Kaffine (2008) show that uncertainty about renewal of a lease, or concession, to harvest a fishery can cause the fishing firm to choose either a 'good stewardship path', where the fish stock is left in good condition at the end of the concession period, or a 'bad stewardship path' where the stock is overexploited. The outcome depends on model parameters, including the natural resource growth rate, length of concession and probability of renewal, all of which are exogenous. In our model exploitation rights are auctioned off at each contract period so the issue of renewal is not relevant.

${ }^{32}$ While we belive that a satisfactory analysis of these issues would require a somewhat different model, and as such is beyond the scope of the present paper, in the Appendix we provide a brief sketch of how the present model could be extended to capture, in an admittedly rather simplistic way, some of the relevant effects.
} 
Another interesting possibility for future research is to take political economy (or public choice) aspects into account. More specifically, different governments may attach different costs to expropriation, depending on their ideology or - in a more Machiavellian vein (cf. Biais and Perotti, 2002) - to what voter groups they fetch their support. Contract length and, more generally, contract structure, may then be utilised to sway the behaviour of the next government towards that of the one in power at present. ${ }^{33}$ This will affect expropriation risk and optimal contract length and could lead to 'cycles' of expropriation and different contract structures.

Finally, it may be possible to apply similar methods as we do here to the related area of sovereign debt and default, cf. the work by Arellano and Ramanarayanan cited in the Introduction. In that setting a stochastic income stream from a tradable good would take the place of resource rent in our model. The aim would be to obtain equilibrium maturity structure and interest rate spreads for sovereign borrowing.

\section{References}

[1] Aghion, Philippe and Lucía Quesada (2010), Petroleum contracts: what does contract theory tell us?, in William Hogan and Federico Sturzenegger (eds.), The Natural Resources Trap: Private Investment Without Public Commitment. Cambridge, Mass: MIT Press.

[2] Arellano, Cristina, and Ananth Ramanarayanan (2012), Default and the maturity structure in sovereign bonds, Journal of Political Economy 120(2), 187-232.

[3] Arnason, Ragnar (2012), Property rights in fisheries: How much can Individual Transferable Quotas accomplish?, Review of Environmental Economics and Policy 6(2), 217-236.

[4] Baldursson, Fridrik M, and Nils-Henrik M von der Fehr (2007), A whiter shade of pale: on the political economy of regulatory instruments, Journal of the European Economic Association 5, 37-65.

[5] Biais, Bruno, and Enrico Perotti (2002), Machiavellian privatization, The American Economic Review 92 (1), 240-258.

[6] Clark, Ephraim (2003), Pricing the cost of expropriation risk, Review of International Economics 11, 412-422.

\footnotetext{
${ }^{33}$ See Baldursson and von der Fehr (2007) for a model of this kind set in the context of environmental regulation. The idea goes back to Persson and Svensson (1989).
} 
[7] Costello, Christopher J., and Daniel Kaffine (2008), Natural resource use with limited-tenure property rights, Journal of Environmental Economics and Management 55(1), 20-36.

[8] Dixit, Avinash and Robert Pindyck (1994), Investment under Uncertainty. Princeton University Press.

[9] Duffie, Darrell (2001), Dynamic Asset Pricing Theory, Third Edition, Princeton University Press.

[10] Eaton, Jonathan, and Mark Gersovitz (1981), Debt with potential repudiation: theoretical and empirical analysis, The Review of Economic Studies, 289-309.

[11] Ellman, Matthew (2006), A Theory of the Optimal Length of Contracts with Application to Outsourcing, Universitat Pompeu Fabra DP 965.

[12] Engel, Eduardo and Ronald Fischer (2010), Optimal resource extraction contracts under threat of expropriation, in William Hogan and Federico Sturzenegger (eds.), The Natural Resources Trap: Private Investment Without Public Commitment. Cambridge, Mass: MIT Press.

[13] Hajzler, Christopher (2012), Expropriation of foreign direct investments: sectoral patterns from 1993 to 2006, Review of World Economics, 148(1), 119-149.

[14] Harris, Milton and Holmstrom, Bengt (1987), On The Duration of Agreements, International Economic Review 28(2), 389-406.

[15] Harstad, Bård (2015), The dynamics of climate agreements, Journal of the European Economic Association, forthcoming.

[16] Hogan, William and Federico Sturzenegger (2010), The Natural Resources Trap: Private Investment Without Public Commitment, MIT Press.

[17] Karatzas, Ioannis and Steven E Shreve (1991). Brownian Motion and Stochastic Calculus, Second Edition. Springer Verlag.

[18] Mahajan, Arvind (1990). Pricing expropriation risk, Financial Management 19, $77-86$.

[19] Persson, Torsten, and Lars EO Svensson (1989), Why a stubborn conservative would run a deficit: Policy with time-inconsistent preferences, The Quarterly Journal of Economics, 325-345. 
[20] Panizza, Ugo, Federico Sturzenegger, and Jeromin Zettelmeyer (2010). The economics and law of sovereign debt and default, Journal of Economic Literature 47(3), 651-698.

[21] Rigobon, Roberto (2010), Dealing with expropriations: general guidelines for oil production contracts, in William Hogan and Federico Sturzenegger (eds.), The Natural Resources Trap: Private Investment Without Public Commitment. Cambridge, Mass: MIT Press.

[22] Schwarz, Eduardo S and Anders B Trolle (2010), Pricing expropriation risk in natural resource contracts, in William Hogan and Federico Sturzenegger (eds.), The Natural Resources Trap: Private Investment Without Public Commitment. Cambridge, Mass: MIT Press.

[23] Summers, Lawrence (2010), Commentary to Philippe Aghion and Lucía Quesada (2010), Petroleum contracts: what does contract theory tell us?, in William Hogan and Federico Sturzenegger (eds.), The Natural Resources Trap: Private Investment Without Public Commitment. Cambridge, Mass: MIT Press..

[24] Thomas, Jonathan and Tim Worrall (1994), Foreign direct investment and the risk of expropriation. The Review of Economic Studies 61(1), 81-108.

[25] Tomz, Michael and Mark LJ Wright (2010), Sovereign theft: theory and evidence about sovereign default and expropriation, in William Hogan and Federico Sturzenegger (eds.), The Natural Resources Trap: Private Investment Without Public Commitment. Cambridge, Mass: MIT Press.

[26] Wernerfelt, Nils and Richard Zeckhauser (2010), Denying the temptation to GRAB, in William Hogan and Federico Sturzenegger (eds.), The Natural Resources Trap: Private Investment Without Public Commitment. Cambridge, Mass: MIT Press.

[27] Zhuang, Juzhong, Zhihong Liang, Tun Lin and Franklin De Guzman (2007), Theory and practice in the choice of social discount rate for cost-benefit analysis: a survey, Working Paper No. 94, Economics and Research Department, Asian Development Bank.

\section{A Infinite contract length}

An infinite contract length, $T=\infty$, corresponds to selling the resource. In this case, i.e. with an infinite time-horizon, the termination boundary becomes a constant, $\bar{r}$. 
Given the lease rate, $l>0$, and $V>0$, the partial-differential equation problem of Section 5.1 reduces to the following ordinary-differential equation problem: find a function $v(r)$ and a constant $\bar{r}$ such that:

$$
\begin{gathered}
\delta v=\mu r v^{\prime}+\frac{1}{2} \sigma^{2} r^{2} v^{\prime \prime}+l \text { for } 0<r<\bar{r}, \\
v(r)=r(V-k), \text { for } r \geqslant \bar{r}, \\
v^{\prime}(r)=V, \text { for } r \geqslant \bar{r},
\end{gathered}
$$

where $v$ must be twice continuously differentiable for $0<r<\bar{r}$ and continuously differentiable across the boundary $\bar{r}$ (this is the 'smooth fit' condition (A.3)).

As with a finitely long contract, the boundary $\bar{r}$ also provides the optimal expropriation strategy, i.e. it is optimal to expropriate the first time the resource rent process hits the expropriation boundary:

$$
\tau=\tau^{*}=\inf \left\{t \geq 0 ; R_{t} \geq \bar{r}\right\}
$$

The above problem is of a well-known type, e.g. similar to analogous infinitehorizon problems solved in Dixit and Pindyck (1994). The general solution to (A.1) is of the form $v(r)=A_{1} r^{\beta_{1}}+A_{2} r^{\beta_{2}}+\frac{l}{\delta}$ where $A_{1}$ and $A_{2}$ are constants and $\beta_{1}>1$ and $\beta_{2}<0$ are the positive and negative roots, respectively, of the characteristic equation $\frac{\sigma^{2}}{2} \beta^{2}+\left(\mu-\frac{\sigma^{2}}{2}\right) \beta-\delta=0$. Since the second term of the general solution will go to infinity as $r$ approaches zero it must hold that $A_{2}=0$. By continuity and smooth fit at the termination boundary we obtain

$$
\begin{array}{r}
\bar{r}=\frac{\beta l}{\delta(\beta-1)(V-k)} \\
A=\frac{V-k}{\beta} \bar{r}^{1-\beta} \\
v(r)=A r^{\beta}+\frac{l}{\delta}
\end{array}
$$

where we drop the indices on $A_{1}$ and $\beta_{1}$ without risk of confusion.

There are two additional complications to this problem over and above what is the norm for problems of this type, viz. that $V$ and the lease rate $l$ are endogenous. More specifically, the lease rate $l$ is determined by the zero-profit condition $(2.7$ on page 9 ) and, since $R_{\tau}=\bar{r}$, we get immediately from ( 2.9 on page 10) that

$$
l=\frac{\delta}{\delta-\mu} \frac{1-\bar{r} E e^{-\delta \tau}-c(\delta-\mu)}{1-E e^{-\delta \tau}} .
$$


Note that $\tau$ is the first-passage time of the geometric Brownian motion to the termination boundary $\bar{r}$. Calculation of the expectation $E e^{-\delta \tau}$ (the Laplace transform of $\tau$ ) is a standard exercise for such stopping times:

$$
E\left[e^{-\delta \tau}\right]=\exp \left[-\frac{\ln \bar{r}}{\sigma^{2}}\left(\sqrt{\left(\mu-\frac{\sigma^{2}}{2}\right)^{2}+2 \sigma^{2} \delta}-\mu+\frac{\sigma^{2}}{2}\right)\right]
$$

The value of $l$ can now be calculated by inserting (A.6) into (A.5).

Since $V=v(1)=A+\frac{l}{\delta}$ we can use (A.4) to derive a non-linear equation for $V$ :

$$
V=\frac{V-k}{\beta}\left(\frac{\beta l}{\delta(\beta-1)(V-k)}\right)^{1-\beta}+\frac{l}{\delta}
$$

The equations ( A.5 on the preceding page) and ( A.7) do not admit a closed form solution, but are easily solved numerically.

The Laplace transform ( A.6) allows for calculation of the expectation (and higher moments) of the time to termination. Differentiating (A.6) and setting $\delta=0$ gives the expected time to expropriation,

$$
E \tau=\frac{\ln \bar{r}}{\mu-\frac{\sigma^{2}}{2}}
$$

\section{B Numerical Computation}

The numerical algorithm for computing an approximation to the resource value and lease rate proceeds by value function iteration. The computation is done over a discrete time grid where the geometric Brownian motion is approximated by a simple geometric random walk. The MATLAB code for the computation is available online at [WEBSITE]. The algorithm proceeds roughly as follows:

1. Values are set for model parameters, $\mu, \sigma, \delta, c$, and $k$.

2. Parameters for the numerical algorithm are set, including length of each discrete timestep $(D T)$, the number of replications of resource rent paths (Nrep) and the parameters of the geometric random walk (see details below).

3. Nrep paths are generated for the resource rent. These are kept fixed throughout the steps below.

4. A value for contract maturity, $T$, is set and an initial guess is made for $V(0,1)$, the equilibrium resource value at $t=0$ and $R_{0}=1$. An initial guess is also made for the corresponding lease rate $l$. 
5. An approximation is computed for $V$ by backwards induction over a discrete time grid, starting at $T$ and approximating the distribution of the geometric Brownian motion by that of a simple geometric random walk. A new approximation of $V(0,1)$ is set to be equal to the computed value of $V$ at $t=0$ and $R_{0}=1$ resulting from the backwards induction. The backwards induction algorithm also delivers an approximation to the expropriation boundary $\bar{r}(t)$.

6. A new approximation for the equilibrium lease rate is computed for $l$ using (2.8), where expectations are approximated by averaging over the previously generated paths of the geometric random walk (Step 3).

7. Steps 5 and 6 are repeated until the combined absolute changes in the approximations for $V(0,1)$ and $l$ are smaller than a preset tolerance.

8. If the difference in $V(0,1)$ from the last approximation is small than a preset tolerance the iteration for a contract of maturity $T$ is ended. Otherwise the algorithm is resumed from Step 5, in a fixed-point iteration, setting intial values of $V(0,1)$ and $l$ to be the last available approximations. If the fixedpoint iteration has not converged after a given number of iterations, then a bisection algorithm is employed to reach the desired precision.

9. The equilibrium solution is found by finding the contract maturity that maximises the resource value $V(0,1)$.

\section{B.1 Approximating the geometric Brownian motion}

Time is measured in steps of length $\Delta$, where $1 / \Delta$ is an even integer. A contract of maturity $T$ corresponds to $N=T / \Delta$ steps and time then runs over the values $\left\{t_{j}=j \Delta ; j=0,1, \ldots, N\right\}$. Note in particular that $t_{0}=0$ and $t_{N}=T$.

The resource rent process $R$ is approximated by a geometric random walk $\hat{R}$, where

$$
\hat{R}_{t_{j+1}}=\left\{\begin{array}{cc}
\hat{R}_{t_{j}} u & \text { with probability } p \\
\hat{R}_{t_{j}} u^{-1} & \text { with probability } 1-p
\end{array}\right.
$$

and

$$
\begin{array}{r}
u=e^{\sigma \sqrt{\Delta}}, \\
p u+(1-p) u^{-1}=e^{\mu \Delta},
\end{array}
$$


which preserves the drift and volatility parameters of the geometric Brownian motion for small values of $\Delta$ (Sigman, 2006). This implies that $E \hat{R}_{t_{j}}=e^{\mu t_{j}}=E R_{t_{j}}$ and $\operatorname{Var}\left(\hat{R}_{t_{j}}\right) \doteq e^{\mu t_{j}}=\operatorname{Var}\left(R_{t_{j}}\right)$.

\section{Utilisation of the resource}

In this appendix, we briefly consider the question of resource utilisation by the leaseholder and its relationship to contract length and expropriation. A full formal analysis of this issue is quite challenging and lies outside the scope of this paper. In what follows we merely sketch a very simple implementation in the setting of Section 2.3.

We assume that the leaseholder needs to make a single, up-front investment in order to utilise the resource and that the larger that investment the larger is the realised resource rent. Hence, in this setting the transaction cost $c$ is interpreted as the cost of investment necessary to achieve a certain degree of resource utilisiation. Moreover, we assume the investment is made immediately after the contract has been entered into, that it cannot be contracted upon in advance and that it cannot be expropriated by the government. Upon expropriation of the contract the investment is lost, both to the leaseholder and the government.

To introduce notation, let $I>0$ be an investment of a leaseholder made at the outset of a contract period. The investment cost is given by an increasing and convex function $c(I)>0$. The flow of realised resource rent at each moment during the lifetime of the contract is given by $\gamma(I) R_{t}$, where $R_{t}$ now stands for an index of potential resource rent (rather than for the flow of resource rent itself) and $\gamma(I)>0$ is an increasing, concave function. Given a contract length, $T$, an expropriation strategy, $\tau$ and a lease rate, $l$, expected profit to the holder of the first contract (leaseholder) is given by

$$
\pi=E\left[\int_{0}^{\tau} e^{-\delta t}\left(\gamma(I) R_{t}-l\right) d t-c(I)\right] .
$$

Note that this equation is the same as (2.6) except that the flow of revenues is given by $\gamma(I) R_{t}$, instead of $R_{t}$, and it is made explicit that $c$ is a function of the initial investment $I$.

Since the investment takes place after the contract has been entered into, the lease rate $l$ and contract length $T$ are taken as given by the leaseholder. Hence, the 
initial investment $I$ is determined by the first-order condition

$$
E\left[\int_{0}^{\tau} \gamma^{\prime}(I) R_{t} e^{-\delta t} d t-c^{\prime}(I)\right]=0
$$

which can be rewritten as

$$
c^{\prime}(I)=\rho(\tau) \gamma^{\prime}(I)
$$

where $\rho(\tau)=E\left[\int_{0}^{\tau} R_{t} e^{-\delta t} d t\right]$ is the expected present value of the potential resource rent index. ${ }^{34}$ Hence, at the optimal level the marginal cost of investment is equal to the marginal expected present value of resource rent.

We are ultimately interested in the relationship between the initial investment and contract length. The latter enters implicitly into (C.3) through its effect on the expropriation strategy $\tau$. Since $\rho(\tau)$ is increasing in $\tau$ (for the moment thinking of $\tau$ as a scalar rather than a stochastic variable) it is easily seen from (C.3) that the larger is $\tau$ the larger is the optimal investment $I$. Hence, if, for each realised path of the resource rent, $\tau$ is increasing in $T$, then $I$ and $c(I)$ will also be increasing in $T$. Unfortunately, we cannot establish this as a general result for each realised path of $R$ (in fact it seems unlikely to be true).

Consider, however, the deterministic case and assume, as in Section 4, that there is an optimal contract $T^{*}$ such that there is no expropriation for $T \leq T^{*}$ and, hence, $\tau \equiv T$. It then follows immediately that initial investment and the associated cost are both increasing in contract length. This is in accordance with intuition: the leaseholder is willing to make a larger initial investment in order to extract a larger flow of rent from the resource provided she reaps the benefits over a longer contract period.

As for the stochastic case, our numerical results indicate that, for a fixed $c, \tau$ is an increasing function of the contract length in expected value terms (cf. Fig. 5.3). Even if here the equilibrium contract length, lease rate and expropriation strategy will be different, one would, intuitively, expect a similar result to continue to hold in this case, in the sense that $\rho(\tau)$ increases with $T$, resulting in a positive relationship between contract length and initial investment.

\footnotetext{
${ }^{34}$ Assuming there is an interior solution to (C.3) it follows from convexity of $c$ and concavity of $\gamma$ that the second-order condition for a maximum is satisfied.
} 